\title{
Micropropagation and conservation of Rheum webbianum collected from Zanaskar valley via tissue culture
}

Shagoon Tabin ${ }^{1,2 *}$, Azra N. Kamilii ${ }^{1}$, R.C. Gupta ${ }^{2}$

${ }^{1}$ Centre of Research for Development, University of Kashmir, Srinagar-190006, India.

${ }^{2}$ Department of Botany, Punjabi university, Patiala, Punjab 147002, India.

Received: 2/27/2018; Revised: 3/15/2018; Accepted: 3/21/2018

Abstract: Rheum webbianum is one of the famous and popular medicinal plant found in Ladakh region. Rheum webbianum Royle is an important medicinal plant belonging to the family Polygonaceae. It is commonly known as 'Himalayan Rhubarb' in English, 'Revandchini' in Hindi, 'xu mi da huang' in Chinese, and 'Lachhu' or 'Chu-rtsa' in Ladakh. It is native to Asia-Temperate to Asia-Tropical, from China to India, Nepal and Pakistan. In India, it is found in Himachal Pradesh, Jammu and Kashmir, Uttar Pradesh. In Jammu and Kashmir, it is grown on open slopes and shrubberies. Due to overexploitation the Rheum webbianum has become endangered. so, it was conserved by the tissue culture and showed best results on different phytohormones. The plant formation was observed on combination of 6-Benzyl Amino Purine, Thidiazuron, 2, 4-Dichlorophenoxyacetic acid and Indole 3-butyric acid.

Key words: Polygonaceae, Tissue culture, micropropagation, endangered, high altitudes, medicinal plants.

\section{Introduction}

In modern medicines, the plants are either directly used as medicine or provide bioactive compounds or raw material for semi synthetic drugs or as markers for discovery of new bioactive compounds (Akerele 1992). As per WHO (World Health Organization) estimation, the present demand for plant based raw material is approximately USD (United States dollar)14 billion per year with 15$25 \%$ annual increase. India is the second largest supplier (next to China only) of raw material of medicinal plants. In India, the medicinal plant related trade is estimated to be USD 1 billion per year (Kala et al., 2006).

In India, most of these medicinal plants (more than $90 \%$ are collected from wild source with unplanned, unscientific and unregulated way leading to shaky, exploitative and unsustainable supply. Further, local people are unaware of morphological features, leading to mixing of different taxa or many cases leading to intentional adulteration (Kala 2000; Schippmann et al., 2006).

India is one of the 12 mega diversity centres of the world (Bapat et al., 2008) and has diverse agroclimatic, ecological and edaphic conditions of the cold deserts of alpine Himalayas, temperate and sub-tropical parts of North-West and trans Himalayas, tropical rain forests of Western Ghats and East India, plains of Central and North India, to the dry deserts of Rajasthan and Gujarat. So, India, in general and Kashmir in particular, is rich in medicinal plant diversity, covering species diversity, genetic diversity and ecosystem diversity (Mukherjee \& Wahile 2006). Out of 18,665

\section{${ }^{*}$ Corresponding Author:}

\section{Dr. Shagoon Tabin Khan,}

Professor,

Centre of Research for Development,

University of Kashmir, Srinagar-190006, India.

E-mail: shagoonkhan@gmail.com
Angiosperms reported from India, about 3000 are used for various medicinal purposes (Schippman $e t$ al, 2006). There is a need to study various macroscopical and microscopical characters of drugs as per WHO and pharmacopoeial guidelines (Anonymous 1996, 1998).

A lot of variations in phyto-pharmaceutical products have been reported which are influenced by genetic diversity (both chromosomal and genetic), environmental factors, plant part used, developmental stage of plant, season of collection, cultivation practices, adulteration with misidentified plant species or intentional mixing, attack of pathogens, etc. (Nadeem et al., 2002, Qu et al., 2004, Murch et al., 2006, Sharma et al., 2009, Prakash et al., 2011, Ramakrishna \& Ravishankar 2011, Sharma 2012, Goyal 2013). Further, due to multi-herbal nature of most of the herbal preparations, it is difficult to identify and quantify the active constituents.

The genus Rheum L. (commonly called Rhubarb), belongs to the family Polygonaceae of group Monochlamydae of Dicots, is world over represented by 60 species (Anjen et al., 2003), of which only 7 species have been reported from the Indian subcontinent (Ganie et al., 2014). According to Stewart (1972), all the seven species (including $R$. webbianum) reported from the Indian subcontinent, are also present in the Kashmir Himalaya. In taxonomical focus, inflorescence is pyramidal or spherical in which flowers are arranged in panicles and pedicel articulates at or below the middle. Rhubarb is derived from the Latin word "rha" 
(river) and "barb" (barbarian land). In ancient times, rhubarb roots were imported by the Romans from barbarian lands which were beyond the Volga or Rha River. According to Lindley's Treasury of Botany, the name is derived from the Greek rheo which means 'to flow'.

A total of 560 plant species of India are included in Red List of Threatened species by IUCN including Rheum species (Phartyal et al., 2002). Rheum is a strong vigorous plant and can live long even in tough conditions. The Rheum species have been domesticated as medicinal plants for human consumption. This species are perennial stout herbs. Rhubarb is a common English name of the genus Rheum and it is distributed in the temperate and sub tropical regions of Himalaya from Kashmir to Sikkim (Nautiyal et al., 2003) and growing wild in the mountains of the Western and North-western provinces of China and adjoining Tibetan territory. It is cultivated much in Europe and the United States. In Kashmir Himalaya, it ranges from an altitude of $1700-5500 \mathrm{~m}$. It is famous for its medicinal uses. Roots are long and stout. Stem is erect, hollow, sulcate, glabrous or strigose. It is native to Asia-Temperate to Asia - Tropical, from China to India, Nepal and Pakistan. In India, its found in Himachal Pradesh Jammu \& Kashmir and Uttar Pradesh. In Jammu and Kashmir, it grows on open slopes and shrubberies in Kashmir, Leh and Zanskar valley between 3,105-3,920 m (Chaurasia et al., 2007). Rheum also prefers a full sunny location and thrives in a moist, fertile soil. Most Rheum species can handle heavier clay soils better than many other herbs and makes a striking addition to the spring landscape. Rhubarb is propagated from seeds, seedlings, or pieces of rhizome.

It is used as a strong laxative and is known for its astringent effect on the mucous membranes of the mouth and nasal cavity (Castleman 1991). Its astringent qualities help to improve bowel tone after it has purged the intestines, making it an excellent agent for improving the tone and health of the digestive tract (Peigen et al., 1984). Its roots have been found useful in controlling gastrointestinal hemorrhage by promoting the formation of blood platelets. This increase in the number of platelets shortens blood clotting time and is helpful in treating jaundice (Borgia et al., 1981). It, therefore, has a truly cleansing action upon the gut, removing debris and then astringing with antiseptic properties (Duke 1997).

R. webbianum is used for treatment of indigestion, abdominal disorders, boils, wounds and flatulence (Chaurausia \& Ballabh 2009). It improves the memory of senile patients (Tayade et al., 2012), helpful in managing cancers (Srinivas et al., 2007).

Tissue culture has now become a well-established technique for culturing and studying the physiological behavior of isolated plant organs, tissues, cells and protoplasts under precisely controlled physical and chemical conditions. Most of the medicinal plants either do not produce seeds or seeds are too small and do not germinate in soils. Thus mass multiplication of disease free planting material is a general problem. In this regard, the micropropagation holds significant promise for true to type, rapid and mass multiplication, and conservation of valuable genotype under disease free conditions (Sen \& Sharma 1991). Cultivation of plant tissue in synthetic media offers an alternative way of producing metabolites of interest to the traditional cultivation in the fields or greenhouses (Dornenburgh \& Knorr 1995, Stockigt et al., 1995, Bourgaud et al., 2001, Ramachandra \& Ravishankar 2002). In successful cases, cell suspension cultures can offer a repeatable method to produce secondary metabolites from elite mother plants with easily controlled conditions and with a continuous supply of material. Genetic transformation may provide increased and efficient system for in vitro production of secondary metabolites. Tissue culture protocols have been developed for several medicinal plants, but there are many other species, which are over exploited in pharmaceutical industries and need conservation. However, genetic transformation is the most recent aspect of plant cell and tissue culture for transfer of genes with desirable trait into host plants and the recovery of transgenic plants (Hinchee et al., 1994). Regeneration of disease or viral resistant plants is now achieved by employing genetic transformation technique. In present studies, the endangered species were grown through tissue culture in order to save this precious plant.

\section{Materials and Methods}

The germplasm of R. webbianum was collected from Ladakh and Zanaskar valley as Shown in Fig. 1-6. The explants taken from field material, including seeds of $R$. webbianum were first washed with tap water to remove the dirt. Then transferred to the beaker, labolene and tween-20, a wetting agent, was poured and kept for 20 minutes. After 20 minutes, the beaker was covered with muslin cloth and was taken under the running tap water so that all the labolene or tween-20 is washed out from explants. Then these were continuously shaken for proper cleaning and were rinsed in pre-autoclaved distilled water. The cleaned plant material was subjected to brief $70 \%$ alcohol rinse and soaked in different sterilant solutions of $\mathrm{HgCl}_{2}$ under laminar air flow cabinet for different time durations to get complete removal of biological contaminants. Seeds were also soaked in water and kept in refrigerator for 3 days. After 3 days, these were taken out, thoroughly washed with running tap water after cleaning them with detergent (labolene) and a few drops of tween20 (surfactant). 
The powder form of MS (Murashige and Skoog medium) was used in present study. In powder form of MS medium, sucrose and agar are absent. These are useful for propagation of plant species requiring nutrients according to the recipe of standard media. In the media, DDW and sucrose was added as per instructions e.g, $30.0 \mathrm{~g}$ of sucrose in 1 litre of MS media. Then $\mathrm{pH}(\sim 5.8)$ was balanced by using $\mathrm{NaOH}(0.1 \mathrm{~N})$ and $\mathrm{HCl}(0.1 \mathrm{~N})$. After balancing the $\mathrm{pH}$, agar was added as per instructions i.e. $8.0 \mathrm{~g} / \mathrm{L}$ in MS media.

In present study, the concentration of phytohormones was used in $\mu \mathrm{M}$. The storage life of stock solutions i.e. auxins and cytokinins was upto one month under the storage temperature of $4^{\circ} \mathrm{C}$. All the glassware, forceps, petriplates, cotton plugs, DDW and beakers were autoclaved before using for tissue culture purposes. After boiling the media, the media was put into the glass vials $(100 \mathrm{ml})$ and were also autoclaved for $20 \mathrm{~min}$. at $121^{\circ} \mathrm{C}$ and $15 \mathrm{lbs} /$ (inch) ${ }^{2}$. Sterilized explants were inoculated onto aseptic nutrient medium under laminar air flow cabinet. The whole process of inoculation was performed under highly aseptic conditions.

After inoculation the cultures were kept in culture room. Cultures were kept for incubation under cool fluorescent tubes at day night regime of 16-hour photoperiod with light intensity of $1500-3000$ lux at a constant temperature of $25 \pm 3{ }^{\circ} \mathrm{C}$. Relative humidity between $60-70 \%$ was maintained.

Subculturing was done after every 3-5 weeks, depending upon the organogenesis and proliferation potential of the explants of culture and was carried out in the Laminar air flow chamber under aseptic conditions. The plantlets obtained from different explants through repeated sub-cultures were finally left in culture vials with open mouth for three days in the incubation room, transferred to plastic pots containing soil-peat mixture and then taken out of incubation room of the lab. Attempts were made to acclimatize plants under the green house facility. Ten replicates were taken for each treatment and observations were recorded at the end of every week. Data were subjected to analysis of variance using SSPP software version 17.0 (SAS Institute Inc., Cary, NC). The growth response of explants under normal conditions and also the effect of plant growth hormone response (PGPR) treatments were considered significant according to the magnitude of the $\mathrm{F}$ value $(\mathrm{P} \leq 0.005)$.

\section{Results}

The explants (leaves, leaf midribs, petioles, rhizomes, roots and shoot tips) from field materials were washed in labolene and tween 20 and then washed under running water for 20 minutes. For surface sterilization, Mercuric chloride $\left(\mathrm{HgCl}_{2}\right)$ was used. The details of the effective treatments for surface sterilization are shown in below

\section{Responses of different Media}

The different explants were cultured on different media i.e. Linsmaier and Skoog (LS), Nitsch and Nitsch (NN), Murashige and Skoog medium (MS), supplemented with different concentration and combinations of phytohormones. But only MS medium showed good response, therefore further experiments were carried out using MS medium.

MS medium with different concentration of Auxins: Effect of MS medium with different concentrations of auxins on callus formation from field grown plant was noted. Different explants (leaf, leaf midrib, petiole, and shoot tips) of $R$. webbianum were taken from field grown plants. The above explants were used for regeneration studies on different Auxins (2,4-D, NAA, IAA, IBA) with concentration varying from $5 \mu \mathrm{M}$ to $10 \mu \mathrm{M}$. But these field explants did not show any proper regeneration. The brownish black callus was observed on MS $+10 \mu \mathrm{M} 2,4-\mathrm{D}$ and $\mathrm{MS}+10 \mu \mathrm{M}$ NAA as shown in Fig. 7-12, respectively.

\section{R. webbianum collected from different altitudes of Kashmir Himalaya.}
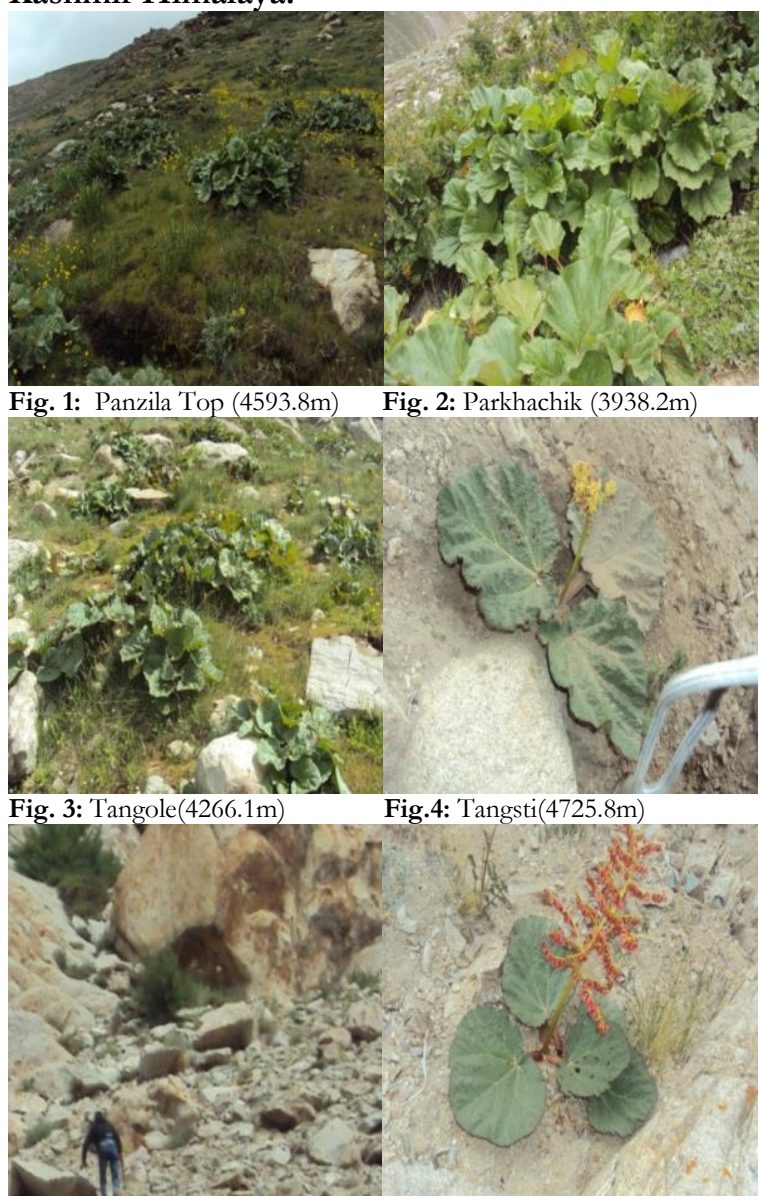

Fig. 5: Khardungla(4921.5m)

Fig. 6: R. webbianum collected from Khardungla. 


\section{Callus formation from field material of $R$. webbianum on different combinations of phytohormones}

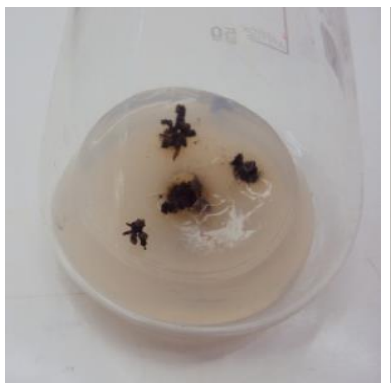

Fig. 7: MS $+10 \mu \mathrm{M} 2,4-\mathrm{D}$

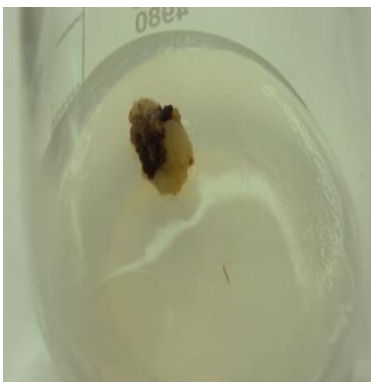

Fig. 10: $10 \mu \mathrm{M}$ TDZ

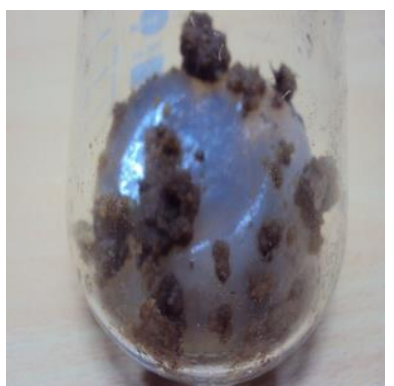

Fig. 8: MS $+10 \mu \mathrm{M}$ NAA

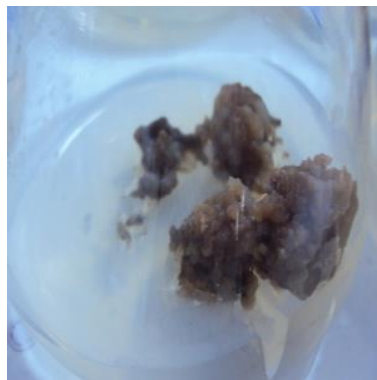

Fig. 11: $10 \mu \mathrm{M} \mathrm{BAP}+7 \mu \mathrm{M} 2,4 \mathrm{D}$

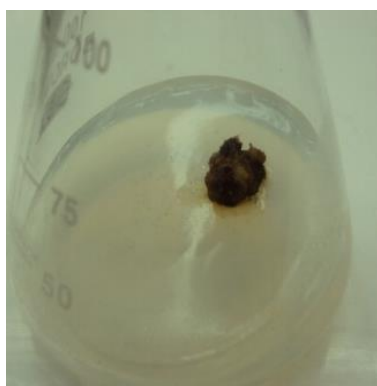

Fig. 9: MS+ $10 \mu \mathrm{M}$ BAP

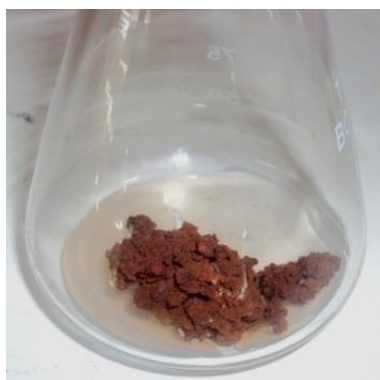

Fig. 12: $10 \mu \mathrm{M}$ TDZ $+7 \mu \mathrm{M} 2,4 \mathrm{D}$

MS medium with different concentration of Cytokinins: Effect of MS medium with different concentrations of cytokinins on callus formation from field grown plants was noted. The $50 \%$ of explants showed the callus formation on different concentrations of cytokinins i.e. MS medium with $10 \mu \mathrm{M}$ BAP and $10 \mu \mathrm{M}$ TDZ as shown in Fig.13-18, respectively

Table 1. Showing the Sterilization and contamination

\begin{tabular}{|c|c|c|c|c|c|}
\hline Sr. No. & $\begin{array}{c}\text { Explants } \\
\text { (Field Material) }\end{array}$ & $\begin{array}{l}\text { Chemical sterilants } \\
\text { (Conc.) } \%\end{array}$ & Duration (min) & Contamination $(\%)$ & Explants survival \% \\
\hline \multirow{4}{*}{1} & \multirow{4}{*}{ Seeds } & $\mathrm{HgCl}_{2}(0.02)$ & 15 & 20 & 70 \\
\hline & & $\mathrm{HgCl}_{2}(0.03)$ & 8 & 20 & 80 \\
\hline & & $\mathrm{HgCl}_{2}(0.05)$ & 10 & 10 & 100 \\
\hline & & $\mathrm{HgCl}_{2}(0.02)$ & 10 & 30 & 50 \\
\hline \multirow[t]{3}{*}{2} & \multirow[t]{2}{*}{ Leaves } & $\mathrm{HgCl}_{2}(0.03)$ & 7 & 30 & 80 \\
\hline & & $\mathrm{HgCl}_{2}(0.05)$ & 5 & 20 & 90 \\
\hline & \multirow{3}{*}{ Petioles } & $\mathrm{HgCl}_{2}(0.01)$ & 10 & 60 & 40 \\
\hline \multirow[t]{3}{*}{3} & & $\mathrm{HgCl}_{2}(0.03)$ & 7 & 50 & 50 \\
\hline & & $\mathrm{HgCl}_{2}(0.05)$ & 5 & 20 & 90 \\
\hline & \multirow{3}{*}{ Leaf Midrib } & $\mathrm{HgCl}_{2}(0.2)$ & 10 & 40 & 80 \\
\hline \multirow[t]{3}{*}{4} & & $\mathrm{HgCl}_{2}(0.03)$ & 10 & 40 & 70 \\
\hline & & $\mathrm{HgCl}_{2}(0.05)$ & 5 & 20 & 80 \\
\hline & \multirow{3}{*}{ Shoot tips } & $\mathrm{HgCl}_{2}(0.1)$ & 5 & 20 & 80 \\
\hline \multirow[t]{2}{*}{5} & & $\mathrm{HgCl}_{2}(0.1)$ & 7 & 40 & 60 \\
\hline & & $\mathrm{HgCl}_{2}(0.03)$ & 10 & 40 & 60 \\
\hline
\end{tabular}

Seed germination of $\boldsymbol{R}$. webbianum

Seed germination studies were carried out using MS medium with different concentrations of phytohormones. Various combinations were used
MS medium with different concentration of Auxins and Cytokinins combination: Effect of MS medium with different concentrations of cytokinins and auxins on callus formation from field grown plant was noted on different combinations but the best result among all was observed on 10 $\mu \mathrm{M} \mathrm{BAP}+7 \mu \mathrm{M} 2,4 \mathrm{D}$ and $10 \mu \mathrm{M}$ TDZ $+7 \mu \mathrm{M}$ 2,4-D as shown in Fig. 22-29, respectively. The callus obtained was further taken for subculturing on the same combinations of phytohormones for further regeneration. for germination but the best results observed are given in Table 2 and Fig. 13-15. These seedlings of $R$. webbianum were further used for regeneration studies as source of various explants i.e. leaves, leaf midrbs, petioles and shoot tips. 


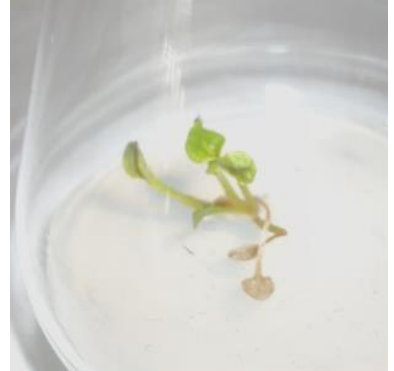

Fig. 13. $10 \mu \mathrm{M} 2,4-\mathrm{D}$

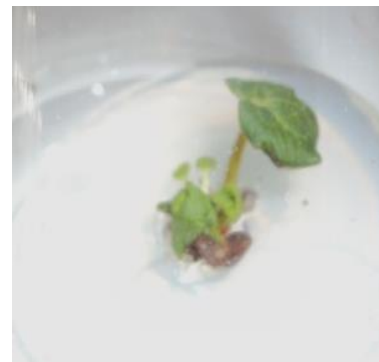

Fig. 16. $10 \mu \mathrm{M}$ BAP

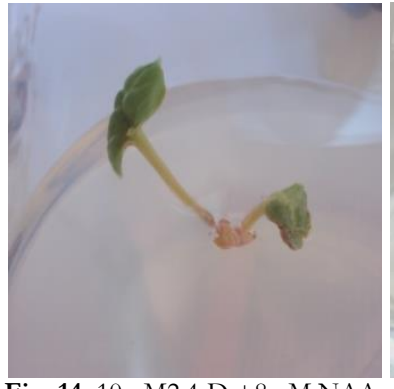

Fig. 14. $10 \mu \mathrm{M} 2,4-\mathrm{D}+8 \mu \mathrm{M}$ NAA

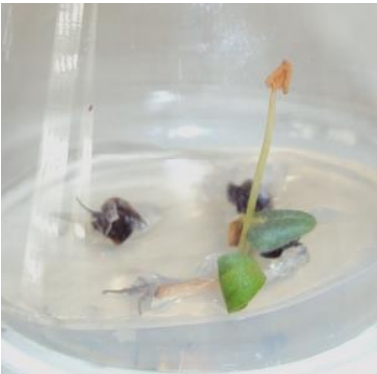

Fig. 15. $10 \mu \mathrm{M} \mathrm{IAA}+10 \mu \mathrm{M} \mathrm{IBA}$
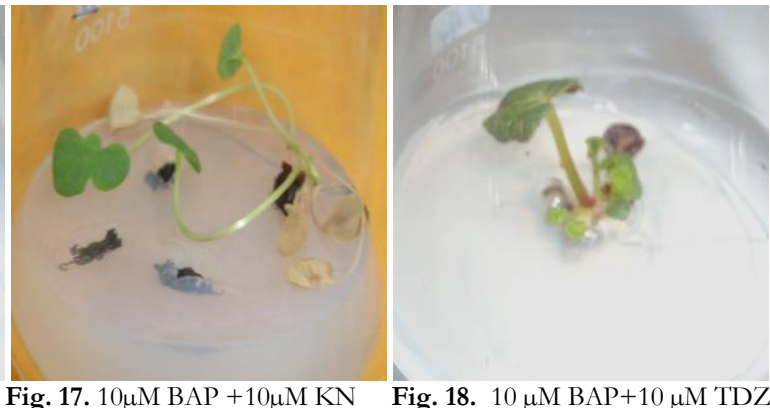

Fig. 17. $10 \mu \mathrm{M}$ BAP $+10 \mu \mathrm{M} \mathrm{KN}$
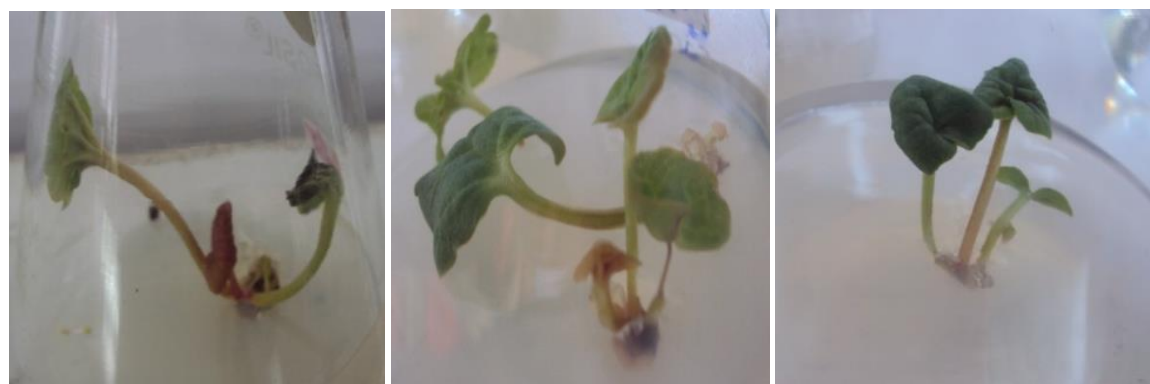

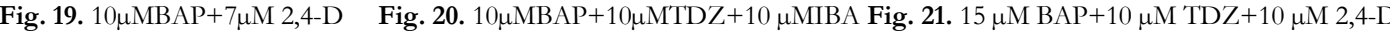

Plant formation through indirect organogenesis on MS medium with different concentrations of phytohormones from callus obtained from leaf (Figs 21 to 24), leaf midrib (Figs 25 to 28), petiole (Figs 21 to 32) and shoot tip explants (Figs 33 to 36) of R. webbianum

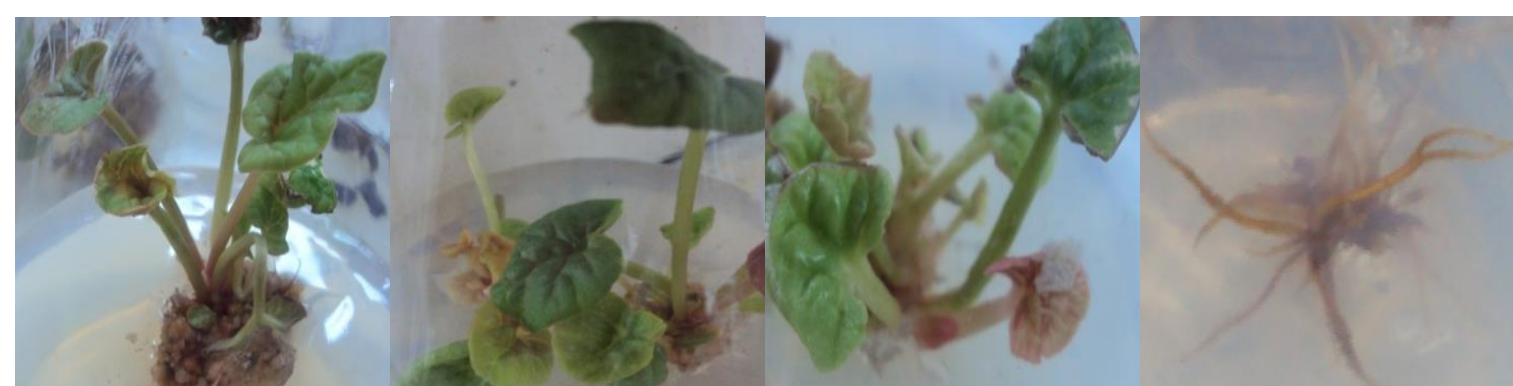

Fig.22. $15 \mu \mathrm{M}$ 2,4-D

Fig.23. $15 \mu \mathrm{M} \mathrm{IBA}$

Fig.24. $15 \mu \mathrm{M}$ BAP

Fig.25.15 $\mu \mathrm{M} \mathrm{BAP}+10 \mu \mathrm{MIBA}$

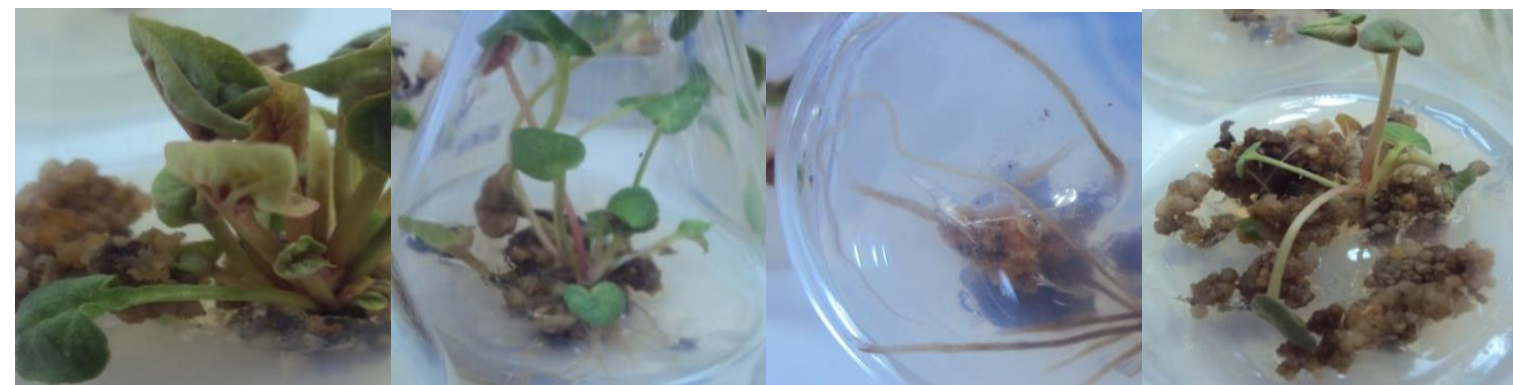

Fig.26. $15 \mu \mathrm{M} 2,4-\mathrm{D}$

Fig.27. $15 \mu \mathrm{M} \mathrm{IBA}$

Fig.28. $15 \mu \mathrm{M}$ BAP

Fig.29. $10 \mu \mathrm{M}$ IBA+15 BAP 


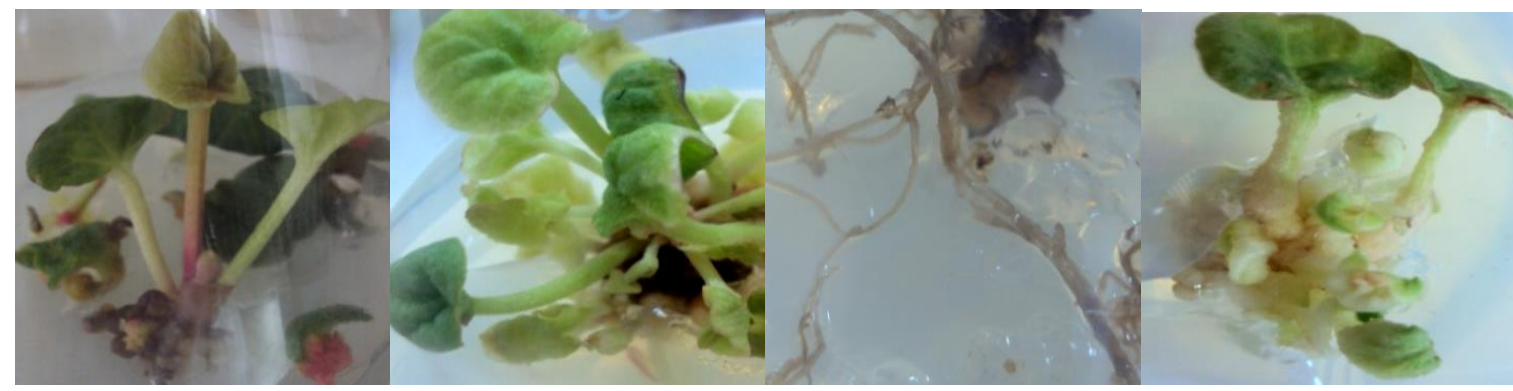

Fig.30. $15 \mu \mathrm{M} 2,4-\mathrm{D}$

Fig.31. $15 \mu \mathrm{M}$ IBA

Fig.32. $15 \mu \mathrm{M}$ BAP

Fig.33. $10 \mu \mathrm{M}$ IBA+15BAP

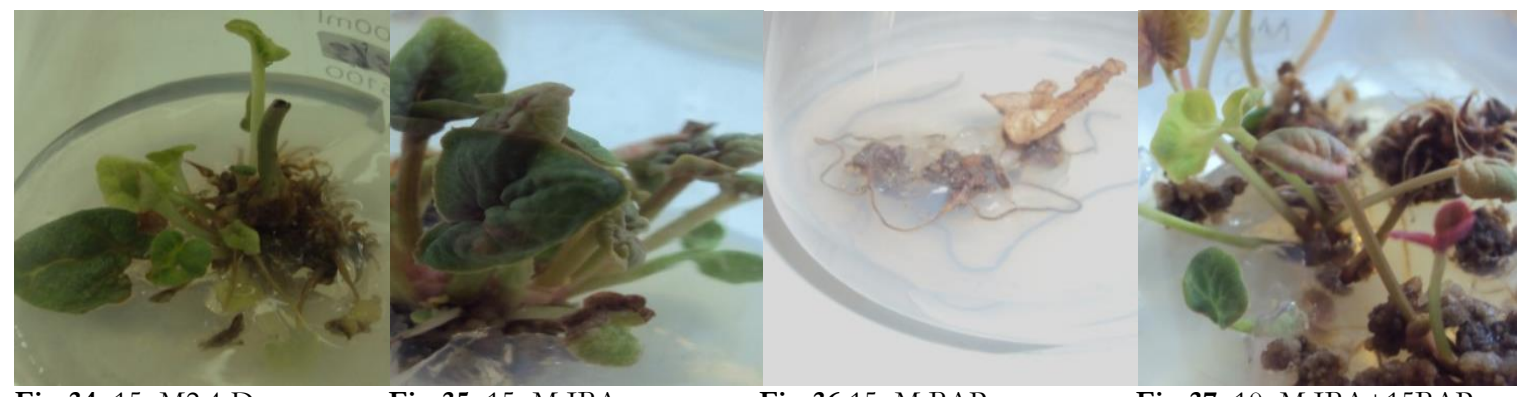

Fig.34. 15 $\mu \mathrm{M} 2,4-\mathrm{D}$

Fig.35. $15 \mu \mathrm{M}$ IBA

Fig.36.15 $\mu \mathrm{M}$ BAP

Fig.37. $10 \mu \mathrm{M}$ IBA+15BAP

Plant formation through direct organogenesis on MS medium with different concentrations of phytohormones from in-vitro explants i.e. leaf (Figs 37 to 40), leaf midrib (Figs 41 to 44), petiole (Figs 45 to 48) and shoot tip explants (Figs 49 to 52) of R. webbianum

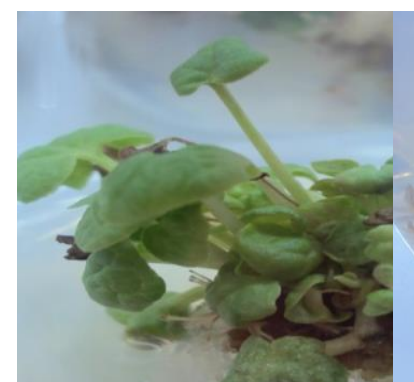

Fig.38. $15 \mu \mathrm{M}$ 2,4-D

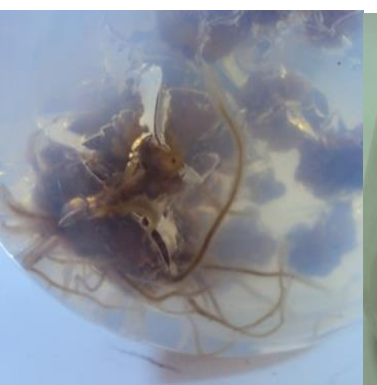

Fig.39. $15 \mu \mathrm{M} \mathrm{IBA}$

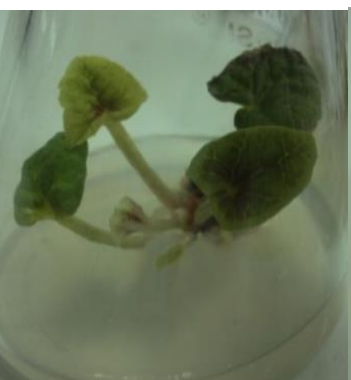

Fig.40. $15 \mu \mathrm{M}$ BAP

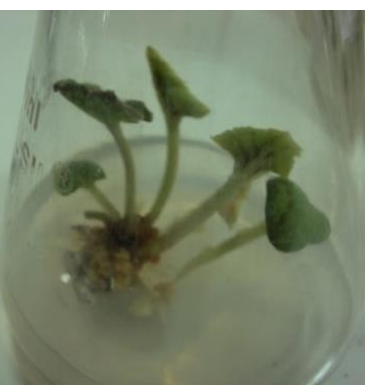

Fig.41. 15 $\mu \mathrm{M} \mathrm{BAP}+10 \mathrm{IBA}$

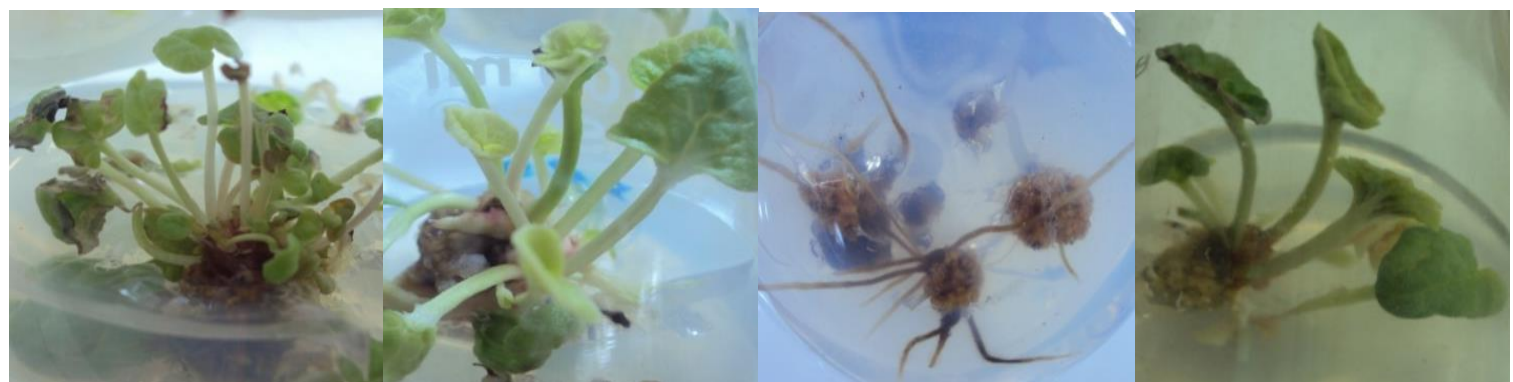

Fig.42. $15 \mu \mathrm{M}$ 2,4-D

Fig.43. $15 \mu \mathrm{M} \mathrm{IBA}$

Fig.44. 15 $\mu \mathrm{M}$ BAP

Fig.45. 15 $\mu \mathrm{M}$ BAP+10IBA

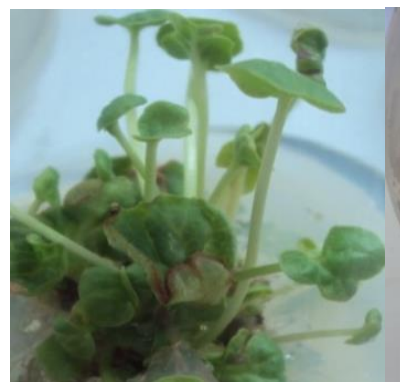

Fig.46. 15 $\mu \mathrm{M}$ 2,4-D

Fig.47. $15 \mu \mathrm{M} \mathrm{IBA}$

Fig.48. 15 $\mu \mathrm{M}$ BAP

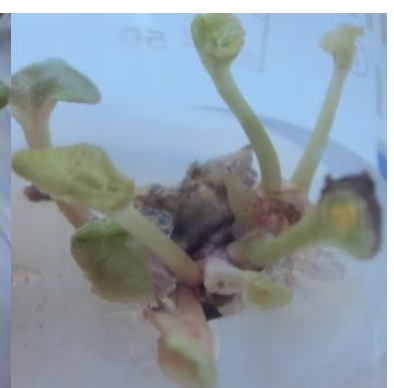

Fig.49. $15 \mu \mathrm{M} \mathrm{BAP}+10 \mathrm{IBA}$ 


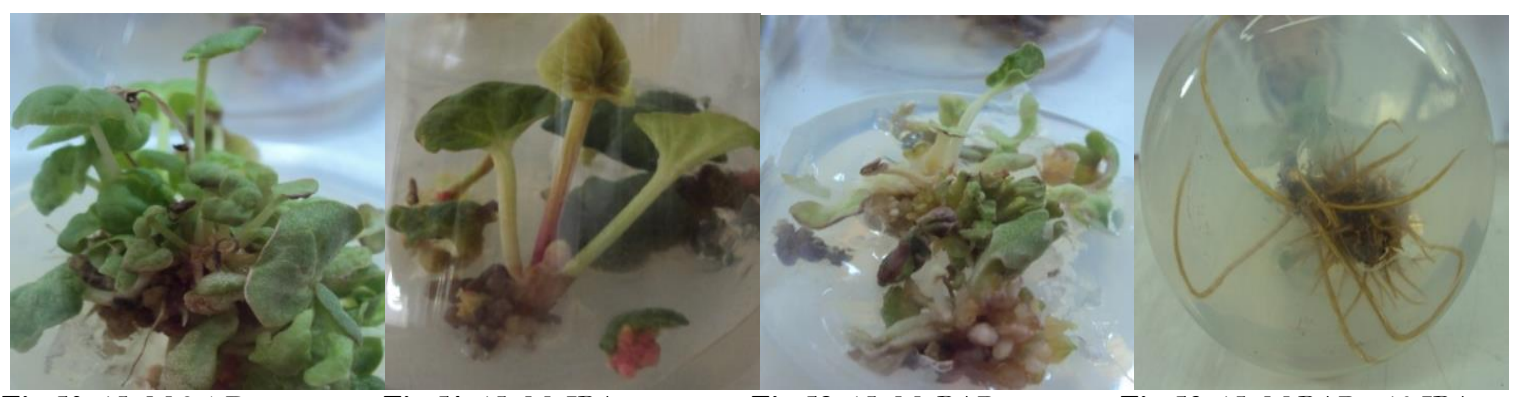

Fig.50. $15 \mu \mathrm{M}$ 2,4-D

Fig.51. $15 \mu \mathrm{M}$ IBA

Fig.52. $15 \mu \mathrm{M} \mathrm{BAP}$

Fig.53. $15 \mu \mathrm{M}$ BAP +10 IBA

Table 2. Response of seed germination on different Leaf culture, Shoot tip culture, petiole culture, media combinations

\begin{tabular}{lcc}
\hline \multicolumn{1}{c}{$\begin{array}{c}\text { Phytohormones } \\
(\text { Conc. in } \boldsymbol{\mu} \mathbf{M})\end{array}$} & $\begin{array}{c}\text { \% seed } \\
\text { germination }\end{array}$ & $\begin{array}{c}\text { \%Plant } \\
\text { formation }\end{array}$ \\
\hline $10.0 \mu \mathrm{M} 2,4-\mathrm{D}$ & 40 & 20 \\
$10.0 \mu \mathrm{M} 2,4-\mathrm{D}+8.0 \mu \mathrm{M} \mathrm{NAA}$ & 40 & 20 \\
$10.0 \mu \mathrm{M} \mathrm{IAA+}+10.0 \mu \mathrm{M} \mathrm{IBA}$ & 40 & 30 \\
$10.0 \mu \mathrm{M} \mathrm{BAP}$ & 50 & 40 \\
$10.0 \mu \mathrm{M} \mathrm{BAP}+10.0 \mu \mathrm{M} \mathrm{KN}$ & 60 & 50 \\
$10.0 \mu \mathrm{M} \mathrm{BAP}+10.0 \mu \mathrm{M} \mathrm{TDZ}$ & 60 & 50 \\
$10.0 \mu \mathrm{MBAP}+10 \mu \mathrm{MTDZ}+10 \mu \mathrm{M} \mathrm{IBA}$ & 60 & 40 \\
$15.0 \mu \mathrm{MBAP}+10.0 \mu \mathrm{M} \mathrm{TDZ}+10.0 \mu \mathrm{M} 2,4-\mathrm{D}$ & 70 & 50 \\
\hline
\end{tabular}

\section{leaf midrib culture}

Indirect organogenesis was observed after further subculturing of callus on same media combinations i.e., regeneration of shoots and roots were observed after 4-6 weeks of sub culturing as shown in Tables 3 to 5. Only rooting was observed on IAA and IBA, when used individually, and the rooting in large number was found on $15 \mu \mathrm{M}$ IBA with $70 \%$ response (Fig.16). However, only shoot regeneration was observed at low concentrations (5-

Regeneration studies on $R$. webbianum using different explants from tissue culture raised seedlings

$10 \mu \mathrm{M})$ of BAP and $\mathrm{Kn}$. The different explants from seedling were used for regeneration studies. After 2 to 3 weeks callus formation was observed.

Callus formation was observed from all the four explants (leaf, leaf mid rib, petiole and shoot tip explants) at different concentrations of auxins and cytokinins individually as well as in combinations after 4-6 weeks of initial inoculation. The weight of callus was in the range of $3.0 \mathrm{~g}$ to $6.0 \mathrm{~g}$.

Regeneration of shoots was observed when the above callus was sub cultured on the same medium after four weeks. The shoot regeneration was observed at higher concentration of auxins i.e. $15 \mu \mathrm{M} 2,4-\mathrm{D}$ and $15 \mu \mathrm{M}$ NAA using different explants as shown in the Fig. a refer to Table 3. The regenerated shoot number was maximum approximately 5 per explants (Fig.17) in case of leaf midrib and shoot tip explants at $15 \mu \mathrm{M}$ 2,4-D (Fig. 18). However, no shooting was observed in case of higher concentration of IBA and IAA. Only rooting was observed from callus.

Table 3. Indirect organogenesis on MS medium with different concentrations of auxins on multiple shoot regeneration/rooting from callus obtained from different explants of R. webbianum

\begin{tabular}{|c|c|c|c|c|c|c|c|c|c|c|c|c|}
\hline $\begin{array}{l}\text { Sr. } \\
\text { No. }\end{array}$ & Explants & $\begin{array}{c}2,4- \\
\mathrm{D} \\
(\mu \mathrm{M})\end{array}$ & $\begin{array}{l}\text { NAA } \\
(\mu \mathrm{M})\end{array}$ & $\begin{array}{l}\text { IAA } \\
(\mu \mathrm{M})\end{array}$ & $\begin{array}{l}\text { IBA } \\
(\mu \mathrm{M})\end{array}$ & $\begin{array}{l}\text { Shoot } \\
\text { No. }\end{array}$ & $\begin{array}{l}\text { Shoot } \\
\text { length } \\
(\mathrm{cm})\end{array}$ & $\begin{array}{c}\text { Leaf } \\
\text { No./shoot }\end{array}$ & $\begin{array}{l}\text { Root } \\
\text { No. }\end{array}$ & $\begin{array}{c}\text { Root } \\
\text { length } \\
(\mathrm{cm})\end{array}$ & Response & $\begin{array}{l}\% \\
\text { response }\end{array}$ \\
\hline \multirow[t]{9}{*}{1.} & Leaf & & & & & & & & & & & \\
\hline & & 12 & - & - & - & a $3.7 \pm 0.5$ & a $1.7 \pm 0.4$ & b $4.9 \pm 0.5$ & ab $2.1 \pm 0.5$ & a1.5 \pm 0.4 & $\begin{array}{l}\text { Indirect } \\
\text { shooting/rooting }\end{array}$ & 60 \\
\hline & & 15 & - & - & - & $\mathrm{b} 4.5 \pm 0.5$ & ab $2.1 \pm 0.5$ & bc $5.1 \pm 0.5$ & b $2.5 \pm 0.5$ & a $1.7 \pm 0.5$ & do & 60 \\
\hline & & - & 12 & - & - & a $3.2 \pm 0.4$ & $\mathrm{a} 1.5 \pm 0.5$ & a3.9 \pm 0.5 & a $1.9 \pm 0.4$ & a $1.4 \pm 0.3$ & do & 60 \\
\hline & & - & 15 & - & - & $3.9 \pm 0.5$ & a $1.9 \pm 0.3$ & $\mathrm{~b} 4.7 \pm 0.5$ & c $3.2 \pm 0.5$ & b2.3 \pm 0.1 & do & 60 \\
\hline & & - & - & 12 & - & nil & nil & nil & $\mathrm{d} 4.2 \pm 0.3$ & b $2.5 \pm 0.3$ & $\begin{array}{l}\text { indirect rooting } \\
\text { only }\end{array}$ & 50 \\
\hline & & - & - & 15 & - & nil & nil & nil & $\mathrm{d} 4.8 \pm 0.5$ & b $2.9 \pm 0.5$ & do & 50 \\
\hline & & - & - & - & 12 & nil & nil & nil & e $5.1 \pm 0.3$ & c $3.2 \pm 0.5$ & do & 50 \\
\hline & & - & - & - & 15 & nil & nil & nil & $\mathrm{e} 5.4 \pm 0.5$ & с $3.5 \pm 0.5$ & do & 50 \\
\hline \multirow[t]{7}{*}{2.} & $\begin{array}{l}\text { Leaf } \\
\text { mid rib }\end{array}$ & & & & & & & & & & & \\
\hline & & 12 & - & - & - & a $3.8 \pm 0.4$ & a1.8 \pm 0.4 & $\operatorname{cb} 5.1 \pm 0.5$ & b2. $2 \pm 0.5$ & a1.7 \pm 0.5 & $\begin{array}{l}\text { indirect } \\
\text { minimum } \\
\text { shooting/rooting }\end{array}$ & 60 \\
\hline & & 15 & - & - & - & b4 $4.9 \pm 0.5$ & b $2.5 \pm 0.5$ & c5.6 \pm 0.5 & 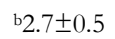 & $\mathrm{a} 1.8 \pm 0.5$ & do & 60 \\
\hline & & - & 12 & - & - & $3.4 \pm 0.5$ & $1.7 \pm 0.5$ & $\mathrm{~b} 4.2 \pm 0.5$ & ba $2.1 \pm 0.5$ & a $1.7 \pm 0.5$ & do & do \\
\hline & & - & 15 & - & - & b $4.3 \pm 0.5$ & b $2.2 \pm 0.1$ & 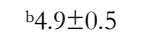 & с3.4 \pm 0.5 & b2. $5 \pm 0.5$ & do & do \\
\hline & & - & - & 12 & - & nil & nil & nil & $\mathrm{d} 4.4 \pm 0.5$ & b $2.7 \pm 0.5$ & $\begin{array}{l}\text { indirect rooting } \\
\text { only }\end{array}$ & 50 \\
\hline & & - & - & 15 & - & nil & nil & nil & $\mathrm{d} 4.8 \pm 0.5$ & c $3.2 \pm 0.5$ & do & 50 \\
\hline
\end{tabular}




\begin{tabular}{|c|c|c|c|c|c|c|c|c|c|c|c|c|}
\hline & & - & - & - & 12 & nil & nil & nil & e $5.4 \pm 0.5$ & с $3.4 \pm 0.5$ & do & 50 \\
\hline & & - & - & - & 15 & nil & nil & nil & e $5.7 \pm 0.5$ & с $3.7 \pm 0.6$ & do & 50 \\
\hline \multirow[t]{9}{*}{3.} & Petiole & & & & & & & & & & & \\
\hline & & 12 & - & - & - & $3.4 \pm 0.3$ & a $1.4 \pm 0.3$ & b $4.5 \pm 0$. & a1.8 \pm 0.3 & $\mathrm{a} 1.3 \pm 0.2$ & $\begin{array}{l}\text { minimum } \\
\text { shooting/rooting }\end{array}$ & 60 \\
\hline & & 15 & - & - & - & b $4.2 \pm 0.2$ & a $1.8 \pm 0.3$ & 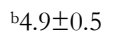 & b $2.2 \pm 0.1$ & a $1.5 \pm 0.2$ & do & 60 \\
\hline & & - & 12 & - & - & a $3.1 \pm 0.2$ & a $1.3 \pm 0.2$ & a $3.7 \pm 0.5$ & a1.7 \pm 0.4 & ${ }^{a} 1.2 \pm 0.3$ & do & 60 \\
\hline & & - & 15 & - & - & a $3.7 \pm 0.5$ & a1.7 \pm 0.3 & b4 $4.5 \pm 0.5$ & $\mathrm{cb} 3.1 \pm 0.5$ & $\mathrm{ab} 2.1 \pm 0.1$ & do & 60 \\
\hline & & - & - & 12 & - & nil & nil & nil & $3.8 \pm 0.2$ & b $2.3 \pm 0.1$ & $\begin{array}{l}\text { indirect rooting } \\
\text { only }\end{array}$ & 50 \\
\hline & & - & - & 15 & - & nil & nil & nil & $\mathrm{d} 4.5 \pm 0.5$ & b $2.6 \pm 0.5$ & do & 50 \\
\hline & & - & - & - & 12 & nil & nil & nil & $\mathrm{d} 4.8 \pm 0.3$ & c3.1 \pm 0.1 & do & 50 \\
\hline & & - & - & - & 15 & nil & nil & nil & e $5.1 \pm 0.4$ & c $3.3 \pm 0.2$ & do & 50 \\
\hline \multirow[t]{9}{*}{4.} & $\begin{array}{l}\text { Shoot } \\
\text { tip }\end{array}$ & & & & & & & & & & & \\
\hline & & 12 & - & - & - & $3.9 \pm 0.5$ & a1.9 \pm 0.4 & c5.2 \pm 0.3 & b2.4 \pm 0.3 & a1.7 \pm 0.4 & $\begin{array}{l}\text { minimum } \\
\text { shooting/rooting }\end{array}$ & 60 \\
\hline & & 15 & - & - & - & b4. $8 \pm 0.5$ & b $2.4 \pm 0.5$ & c $5.8 \pm 0.5$ & b $2.7 \pm 0.5$ & a $1.9 \pm 0.5$ & do & 60 \\
\hline & & - & 12 & - & - & $3.5 \pm 0.4$ & a $1.7 \pm 0.5$ & b4. $5 \pm 0.4$ & b2.5 \pm 0.3 & a $1.7 \pm 0.5$ & $\begin{array}{l}\text { minimum } \\
\text { shooting/rooting }\end{array}$ & 60 \\
\hline & & - & 15 & - & - & b4 $4 \pm 0.5$ & b2.3 $2 \pm 0.2$ & b4.9 \pm 0.5 & c3.6 \pm 0.5 & b2.5 \pm 0.3 & do & 60 \\
\hline & & - & - & 12 & - & nil & nil & nil & $\mathrm{d} 4.7 \pm 0.5$ & b $2.9 \pm 0.5$ & $\begin{array}{l}\text { indirect rooting } \\
\text { only }\end{array}$ & 50 \\
\hline & & - & - & 15 & - & nil & nil & nil & $\mathrm{e} 5.5 \pm 0.5$ & с $3.5 \pm 0.5$ & do & 50 \\
\hline & & - & - & - & 12 & nil & nil & nil & e $5.7 \pm 0.3$ & c3.8 \pm 0.5 & do & 50 \\
\hline & & - & - & - & 15 & nil & nil & nil & e $5.9 \pm 0.7$ & $\mathrm{~d} 4.2 \pm 0.5$ & do & 50 \\
\hline
\end{tabular}

Values are represented as mean \pm SD $(\mathrm{n}=10)$, Data was analyzed by ANOVA using Duncan's multiple range test (SPSS17.0); the values with different superscript along the columns are statistically significant at $\mathrm{P}<0.005$, Data scored after 12 weeks of culture period

Fig. a: Effect of Auxins on shoot regeneration from callus originated from different explants

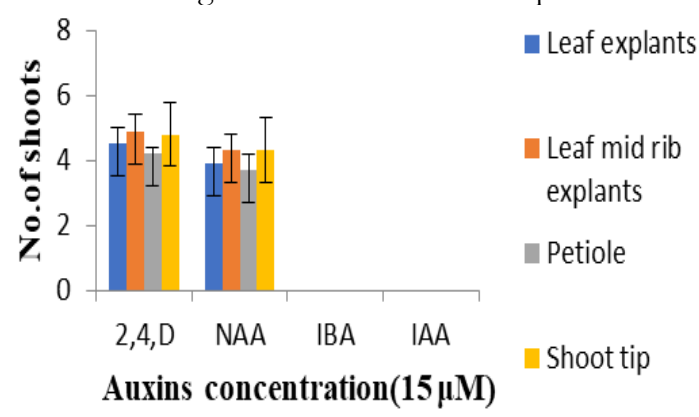

The effect of cytokinins were studied using different explants as shown in Fig.b refer to the Table 4. The maximum number of shoots regeneration from callus was observed on $15 \mu \mathrm{M}$ of cytokinins i.e. BAP, TDZ and $\mathrm{Kn}$ from all the explants. However, in case of shoot tip explants the number of regenerated shoots was maximum i.e. 6 shoots per explants at $15 \mu \mathrm{M}$ BAP.

Table 4. Indirect organogenesis on MS medium with different concentrations of cytokinins on multiple shoot regeneration/rooting from callus obtained from different explants of R. webbianum

\begin{tabular}{|c|c|c|c|c|c|c|c|c|c|c|c|c|}
\hline $\begin{array}{l}\text { Sr. } \\
\text { No. }\end{array}$ & Explants & $\begin{array}{l}\text { BAP } \\
(\mu \mathrm{M})\end{array}$ & $\begin{array}{l}\text { TDZ } \\
(\mu \mathrm{M})\end{array}$ & $\begin{array}{c}\mathrm{KN} \\
(\mu \mathrm{M})\end{array}$ & $\begin{array}{c}\mathrm{Z} \\
(\mu \mathrm{M})\end{array}$ & $\begin{array}{l}\text { Shoot } \\
\text { No. }\end{array}$ & $\begin{array}{l}\text { Shoot } \\
\text { length } \\
(\mathrm{cm})\end{array}$ & $\begin{array}{c}\text { Leaf } \\
\text { No./shoot }\end{array}$ & $\begin{array}{l}\text { Root } \\
\text { No. }\end{array}$ & $\begin{array}{l}\text { Root } \\
\text { length } \\
\text { (cm) }\end{array}$ & Response & $\begin{array}{l}\% \\
\text { response }\end{array}$ \\
\hline \multirow[t]{7}{*}{1.} & Leaf & & & & & & & & & & & \\
\hline & & 12 & - & - & - & с $5.2 \pm 0.5$ & ab $2.1 \pm 0.4$ & dc $6.1 \pm 0.5$ & Nil & Nil & $\begin{array}{l}\text { indirect shooting } \\
\text { only } \\
\text { indirect }\end{array}$ & 70 \\
\hline & & 15 & - & - & - & c5.8 \pm 0.6 & b $2.2 \pm 0.5$ & $\mathrm{~d} 6.9 \pm 0.5$ & Nil & nil & $\begin{array}{l}\text { maximun } \\
\text { shooting }\end{array}$ & 70 \\
\hline & & - & 12 & - & - & b4. $8 \pm 0.2$ & a1.8 \pm 0.3 & $c 5.8 \pm 0.5$ & a $1.7 \pm 0.3$ & a $1.2 \pm 0.4$ & $\begin{array}{l}\text { infirect } \\
\text { shooting/rooting } \\
\text { indirect }\end{array}$ & 70 \\
\hline & & - & 15 & - & - & c5.3 \pm 0.6 & ab $2.1 \pm 0.2$ & dc $6.1 \pm 0.3$ & a $1.9 \pm 0.5$ & a $1.5 \pm 0.1$ & $\begin{array}{l}\text { maximum } \\
\text { shooting/rooting }\end{array}$ & 70 \\
\hline & & - & - & 12 & - & b4.9 \pm 0.3 & $1.3 \pm 0.2$ & $5.3 \pm 0.4$ & $1.6 \pm 0.3$ & a $1.2 \pm 0.5$ & $\begin{array}{l}\text { indirect } \\
\text { shooting/rooting } \\
\text { indirect }\end{array}$ & 70 \\
\hline & & - & - & 15 & - & c5.2 \pm 0.2 & a $1.5 \pm 0.3$ & 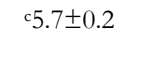 & a $1.8 \pm 0.3$ & a1.4 \pm 0.2 & $\begin{array}{l}\text { maximum } \\
\text { shooting/rooting }\end{array}$ & 70 \\
\hline \multirow[t]{6}{*}{2.} & $\begin{array}{l}\text { Leaf } \\
\text { mid rib }\end{array}$ & & & & & & & & & & & \\
\hline & & 12 & - & - & - & с $5.5 \pm 0.5$ & b2.3 \pm 0.4 & $\mathrm{~d} 6.4 \pm 0.5$ & Nil & Nil & $\begin{array}{l}\text { indirect shooting } \\
\text { only }\end{array}$ & 70 \\
\hline & & 15 & - & - & - & 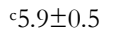 & b $2.4 \pm 0.5$ & e $7.2 \pm 0.1$ & a $1.5 \pm 0.3$ & $\mathrm{a} 1.7 \pm 0.2$ & do & 70 \\
\hline & & - & 12 & - & - & 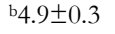 & ${ }^{\mathrm{a}} 1.9 \pm 0.5$ & c5.9 \pm 0.5 & a1.9 \pm 0.4 & $\mathrm{a} 1.4 \pm 0.5$ & do & 70 \\
\hline & & - & 15 & - & - & c5.6 \pm 0.6 & b $2.4 \pm 0.5$ & $\mathrm{~d} 6.4 \pm 0.3$ & b $2.5 \pm 0.5$ & a $1.7 \pm 0.3$ & do & 70 \\
\hline & & - & - & 12 & - & с $5.1 \pm 0.3$ & ${ }^{a} 1.6 \pm 0.2$ & c5.7 \pm 0.4 & ${ }^{a} 1.8 \pm 0.5$ & a1.4 \pm 0.5 & do & 70 \\
\hline
\end{tabular}




\begin{tabular}{|c|c|c|c|c|c|c|c|c|c|c|c|c|}
\hline \multirow{7}{*}{3.} & & - & - & 15 & - & 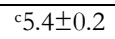 & a $1.7 \pm 0.3$ & $\mathrm{dc} 6.1 \pm 0.2$ & a1.9 \pm 0.4 & 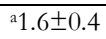 & do & 70 \\
\hline & Petiole & 12 & - & - & - & bc $5.0 \pm 0.1$ & 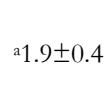 & c5.8 \pm 0.5 & Nil & Nil & $\begin{array}{l}\text { indirect shooting } \\
\text { only }\end{array}$ & 60 \\
\hline & & 15 & - & - & - & с $5.5 \pm 0.6$ & $\mathrm{a} 1.2 \pm 0.5$ & $\mathrm{~d} 6.9 \pm 0.5$ & Nil & nil & do & 60 \\
\hline & & - & 12 & - & - & b $4.6 \pm 0.2$ & a $1.6 \pm 0.3$ & 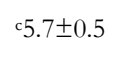 & a $1.5 \pm 0.3$ & a $1.1 \pm 0.2$ & $\begin{array}{l}\text { indirct } \\
\text { shooting/rooting }\end{array}$ & 60 \\
\hline & & - & 15 & - & - & bc $5.1 \pm 0.2$ & a $1.9 \pm 0.3$ & 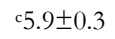 & a $1.7 \pm 0.5$ & $\mathrm{a} 1.3 \pm 0.1$ & do & 60 \\
\hline & & - & - & 12 & - & b $4.7 \pm 0.3$ & $\mathrm{a} 1.2 \pm 0.1$ & $5.1 \pm 0.3$ & $\mathrm{a} 1.4 \pm 0.2$ & $\mathrm{a} 1.1 \pm 0.2$ & do & 60 \\
\hline & & - & - & 15 & - & bc $5.0 \pm 0.1$ & a $1.3 \pm 0.2$ & c5.5 \pm 0.2 & a1.6 \pm 0.3 & $\mathrm{a} 1.2 \pm 0.1$ & do & 60 \\
\hline \multirow[t]{7}{*}{4.} & $\begin{array}{l}\text { Shoot } \\
\text { tip }\end{array}$ & & & & & & & & & & & \\
\hline & & 12 & - & - & - & с5.4 \pm 0.3 & b $2.5 \pm 0.4$ & $\mathrm{~d} 6.4 \pm 0.5$ & Nil & Nil & $\begin{array}{l}\text { indirect shooting } \\
\text { only } \\
\text { maximum }\end{array}$ & 70 \\
\hline & & 15 & - & - & - & $\mathrm{d} 6.2 \pm 0.1$ & b $2.5 \pm 0.3$ & e $7.3 \pm 0.5$ & a $1.9 \pm 0 \pm 3$ & $\mathrm{a} 1.5 \pm 0.2$ & $\begin{array}{l}\text { indirect } \\
\text { shooting/rooting }\end{array}$ & 70 \\
\hline & & - & 12 & - & - & c $5.2 \pm 0.2$ & b $2.3 \pm 0.2$ & $\mathrm{~d} 6.2 \pm 0.5$ & a1.9 \pm 0.5 & a1.4 \pm 0.2 & do & 70 \\
\hline & & - & 15 & - & - & c5.6 \pm 0.5 & b $2.3 \pm 0.2$ & $\mathrm{~d} 6.4 \pm 0.4$ & b $2.3 \pm 0.5$ & a $1.7 \pm 0.2$ & do & 70 \\
\hline & & - & - & 12 & - & c $5.2 \pm 0.1$ & $1.6 \pm 0.2$ & $5.7 \pm 0.3$ & $1.9 \pm 0.5$ & $1.5 \pm 0.5$ & do & 70 \\
\hline & & - & - & 15 & - & с $5.4 \pm 0.2$ & a1.7 \pm 0.3 & 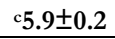 & ba $2.1 \pm 0.1$ & a1.6 \pm 0.4 & do & 70 \\
\hline
\end{tabular}

Values are represented as mean \pm SD ( $\mathrm{n}=10)$, Data was analyzed by ANOVA using Duncan's multiple range test (SPSS17.0); the values with different superscript along the columns are statistically significant at $\mathrm{P}<0.005$, Data scored after 12 weeks of culture period

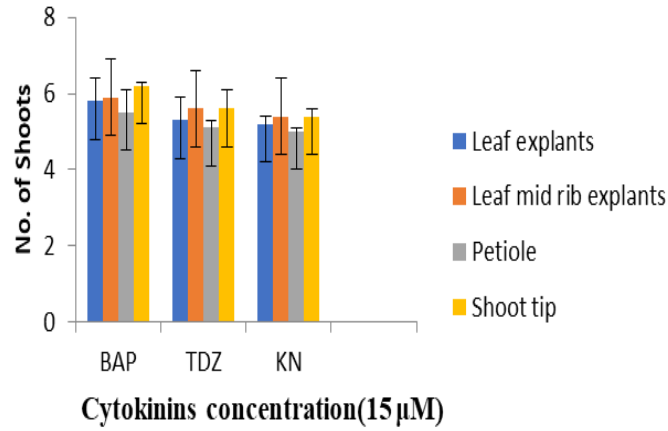

Cytokinins on shoot regeneration from callus originated from different explants

The effect of combination of phytohormones i.e. cytokinins with auxins on fixed concentration of $15 \mu \mathrm{M}$ was studied as shown in the Fig. c refer to the table 5. The shoot tip showed maximum shoot regeneration from callus on $15 \mu \mathrm{M}$ BAP with $15 \mu \mathrm{M}$ IBA i.e. 10 shoots per explants (Fig. 19).
Fig. c. Effect of BAP $15(\mu \mathrm{M})$ with different auxins on shoot regeneration from callus

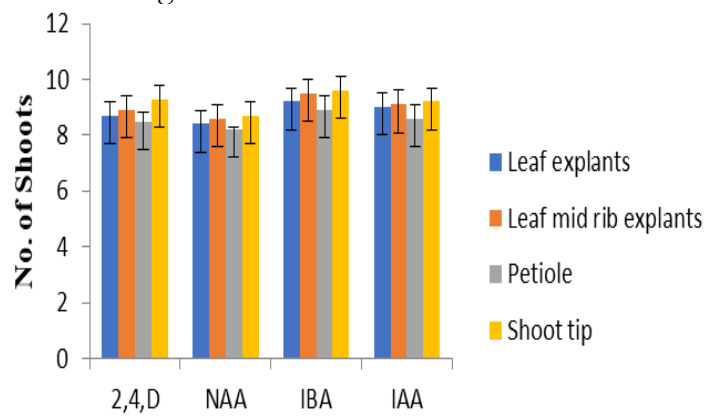

Auxins concentration $(15 \mu \mathrm{M})$

Table 5. Indirect organogenesis on MS medium with $15 \mu \mathrm{M}$ BAP and different concentrations of auxins on multiple shoot regeneration/rooting from callus obtained from different explants of R. webbianum

\begin{tabular}{|c|c|c|c|c|c|c|c|c|c|c|c|c|}
\hline \multirow[b]{2}{*}{$\begin{array}{l}\text { Sr. } \\
\text { No. }\end{array}$} & \multicolumn{2}{|l|}{ Cytokinin } & \multicolumn{2}{|c|}{ Auxins } & \multirow[b]{2}{*}{$\begin{array}{c}\text { IAA } \\
(\mu \mathbf{M})\end{array}$} & \multirow[b]{2}{*}{$\begin{array}{l}\text { Shoot } \\
\text { No. }\end{array}$} & \multirow[b]{2}{*}{$\begin{array}{l}\text { Shoot } \\
\text { length } \\
\text { (cm) }\end{array}$} & \multirow[b]{2}{*}{ Leaf no. } & \multirow[b]{2}{*}{$\begin{array}{c}\text { Root } \\
\text { No }\end{array}$} & \multirow[b]{2}{*}{$\begin{array}{c}\text { Root } \\
\text { length } \\
(\mathrm{cm})\end{array}$} & \multirow[b]{2}{*}{ Response } & \multirow[b]{2}{*}{$\begin{array}{c}\% \\
\text { Response }\end{array}$} \\
\hline & $\begin{array}{l}\text { BAP } \\
(\mu \mathrm{M})\end{array}$ & $\begin{array}{c}2,4- \\
\mathrm{D} \\
(\mu \mathrm{M})\end{array}$ & $\begin{array}{l}\text { NAA } \\
(\mu \mathbf{M})\end{array}$ & $\begin{array}{c}\text { IBA } \\
(\mu \mathbf{M})\end{array}$ & & & & & & & & \\
\hline \multirow[t]{5}{*}{1.} & Leaf & & & & & & & & & & & \\
\hline & 15 & 15 & & & & $\mathrm{~d} 8.7 \pm 0.5$ & c $3.5 \pm 0.2$ & g9.9 \pm 0.5 & с $3.5 \pm 0.2$ & b2.7 \pm 0.5 & $\begin{array}{l}\text { Multiplication } \\
\text { /elongation/ } \\
\text { rooting }\end{array}$ & 70 \\
\hline & 15 & & 15 & & & $\mathrm{~d} 8.4 \pm 0.5$ & bс $3.1 \pm 0.2$ & $\mathrm{~g} 9.1 \pm 0.3$ & c $3.7 \pm 0.3$ & b2.9 \pm 0.5 & do & 70 \\
\hline & 15 & & & 15 & & e $9.2 \pm 0.5$ & c $3.5 \pm 0.3$ & $\mathrm{~h} 10.5 \pm 0.5$ & e $5.7 \pm 0.5$ & $\operatorname{cd} 4.1 \pm 0.3$ & do & 70 \\
\hline & 15 & & & & 15 & e9. $0 \pm 0.5$ & c3.0 \pm 0.3 & h $10.1 \pm 0.5$ & e $5.4 \pm 0.5$ & 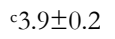 & do & 70 \\
\hline \multirow[t]{5}{*}{2.} & Mid rib & & & & & & & & & & & \\
\hline & 15 & 15 & & & & $\mathrm{~d} 8.9 \pm 0.5$ & c3.6 \pm 0.2 & $\mathrm{hg} 10.1 \pm 0.5$ & c3.6 \pm 0.2 & ь2 $2.9 \pm 0.5$ & do & 70 \\
\hline & 15 & & 15 & & & $\mathrm{~d} 8.6 \pm 0.5$ & c $3.3 \pm 0.2$ & $g 9.3 \pm 0.4$ & с $3.9 \pm 0.3$ & с $3.3 \pm 0.5$ & do & 70 \\
\hline & 15 & & & 15 & & e $9.5 \pm 0.5$ & с $3.7 \pm 0.3$ & $\mathrm{~h} 10.7 \pm 0.5$ & อ $5.9 \pm 0.5$ & $\mathrm{~d} 4.3 \pm 0.3$ & do & 70 \\
\hline & 15 & & & & 15 & e9.1 \pm 0.5 & 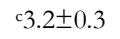 & $\mathrm{h} 10.2 \pm 0.5$ & e $5.3 \pm 0.5$ & $\mathrm{~d} 4.1 \pm 0.3$ & do & \\
\hline \multirow[t]{5}{*}{3.} & Petiole & & & & & & & & & & & \\
\hline & 15 & 15 & & & & $\mathrm{~d} 8.5 \pm 0.3$ & c $3.2 \pm 0.2$ & $89.7 \pm 0.5$ & c $3.3 \pm 0.2$ & c2.5 \pm 0.3 & do & 70 \\
\hline & 15 & & 15 & & & $\mathrm{~d} 8.2 \pm 0.1$ & b $2.9 \pm 0.2$ & f $8.8 \pm 0.4$ & c $3.5 \pm 0.2$ & c $2.7 \pm 0.3$ & do & 70 \\
\hline & 15 & & & 15 & & $\mathrm{~d} 8.9 \pm 0.5$ & c $3.6 \pm 0.3$ & $g 9.9 \pm 0.5$ & e $5.6 \pm 0.3$ & c $3.9 \pm 0.3$ & do & 70 \\
\hline & 15 & & & & 15 & $\mathrm{~d} 8.6 \pm 0.5$ & с $3.3 \pm 0.3$ & $\mathrm{~g} 9.7 \pm 0.5$ & e $5.3 \pm 0.3$ & c $3.5 \pm 0.3$ & do & 70 \\
\hline \multirow[t]{2}{*}{4.} & Shoot tip & & & & & & & & & & & \\
\hline & 15 & 15 & & & & e9.3 \pm 0.5 & c3.7 \pm 0.2 & h1 $10.5 \pm 0.5$ & с3.7 \pm 0.5 & b2.9 \pm 0.5 & do & 70 \\
\hline
\end{tabular}




\begin{tabular}{|c|c|c|c|c|c|c|c|c|c|}
\hline 15 & 15 & & $\mathrm{~d} 8.7 \pm 0.5$ & 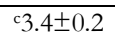 & h10.3 \pm 0.3 & c3.9 \pm 0.5 & 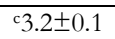 & do & 70 \\
\hline 15 & 15 & & e9.6 \pm 0.5 & c3.8 \pm 0.3 & h10.8 \pm 0.5 & e $5.9 \pm 0.5$ & $\mathrm{~d} 4.4 \pm 0.3$ & do & 70 \\
\hline 15 & & 15 & e9.2 \pm 0.5 & c $3.4 \pm 0.3$ & h10.4 \pm 0.5 & e $5.6 \pm 0.5$ & $\mathrm{~d} 4.1 \pm 0.3$ & do & 70 \\
\hline
\end{tabular}

The different concentrations and combinations of phytohormones were used for regeneration studies from different explants of $R$. webbianum, out of which the $15 \mu \mathrm{M}$ BAP with $15 \mu \mathrm{M}$ IBA combination showed good results. The regenerated shoot number on $15 \mu \mathrm{M}$ concentration of $\mathrm{BAP}$ with different auxins i.e. 2,4-D, NAA, IBA and IAA was found to be more than 8 per explants in all the explants (Fig. 20).

Direct organogenesis from different in-vitro explants of $\boldsymbol{R}$. webbianum

The plants developed from callus of explants (originated from seedlings) were used as a source of in-vitro explants which were further used for regeneration studies i.e. direct organogenesis with minimum callus formation on different combinations of phytohormones. The different explants used for direct regeneration were leaf, leaf midrib, petiole and shoot tip.

The in-vitro explants were sub-cultured on different concentrations of phytohormones starting from 5 $\mu \mathrm{M}$ to $15 \mu \mathrm{M}$ but the best results were found on high concentrations of phytohormones. The regeneration data collected from above experiments was analysed by ANOVA using Duncan's multiple test as shown in Table 6 to 8 .

Table 6. Direct organogenesis on MS medium with different concentrations of auxins on multiple shoot regeneration/rooting from in-vitro explants of R. webbianum

\begin{tabular}{|c|c|c|c|c|c|c|c|c|c|c|c|c|}
\hline $\begin{array}{l}\text { Sr. } \\
\text { No. }\end{array}$ & Explants & $\begin{array}{c}2,4- \\
\mathrm{D} \\
(\mu \mathrm{M})\end{array}$ & $\begin{array}{l}\text { NAA } \\
(\mu \mathrm{M})\end{array}$ & $\begin{array}{l}\text { IAA } \\
(\mu \mathrm{M})\end{array}$ & $\begin{array}{l}\text { IBA } \\
(\mu \mathrm{M})\end{array}$ & $\begin{array}{l}\text { Shoot } \\
\text { No. }\end{array}$ & $\begin{array}{c}\text { Shoot } \\
\text { length } \\
(\mathrm{cm})\end{array}$ & $\begin{array}{c}\text { Leaf } \\
\text { No./shoot }\end{array}$ & $\begin{array}{l}\text { Root } \\
\text { No. }\end{array}$ & $\begin{array}{c}\text { Root } \\
\text { length } \\
\text { (cm) }\end{array}$ & Response & $\begin{array}{l}\% \\
\text { response }\end{array}$ \\
\hline \multirow[t]{9}{*}{1.} & Leaf & & & & & & & & & & & \\
\hline & & 12 & - & - & - & a $3.8 \pm 0.5$ & a1.8 \pm 0.4 & c5.2 \pm 0.3 & b $2.3 \pm 0.2$ & a $1.7 \pm 0.4$ & $\begin{array}{l}\text { minimum } \\
\text { shooting/rooting }\end{array}$ & 60 \\
\hline & & 15 & - & - & - & b $4.6 \pm 0.4$ & b $2.3 \pm 0.5$ & с $5.4 \pm 0.5$ & ${ }^{\mathrm{b}} 2.7 \pm 0.5$ & a $1.9 \pm 0.3$ & do & 60 \\
\hline & & - & 12 & - & - & $\mathrm{a} 3.4 \pm 0.4$ & a $1.7 \pm 0.5$ & ab $4.2 \pm 0.3$ & b2.3 20.4 & a $1.7 \pm 0.3$ & do & 60 \\
\hline & & - & 15 & - & - & b $4.3 \pm 0.2$ & b2.3 \pm 0.2 & b4.9 \pm 0.5 & c3.4 \pm 0.5 & b2.5 \pm 0.3 & do & 60 \\
\hline & & - & - & 12 & - & nil & nil & nil & $4.9 \pm 0.5$ & c $3.2 \pm 0.4$ & direct rooting only & 50 \\
\hline & & - & - & 15 & - & nil & nil & nil & $5.6 \pm 0.5$ & с3.5 \pm 0.5 & do & 50 \\
\hline & & - & - & - & 12 & nil & nil & nil & $5.2 \pm 0.5$ & $\mathrm{~d} 4.2 \pm 0.8$ & do & 50 \\
\hline & & - & - & - & 15 & nil & nil & nil & $6.3 \pm 0.5$ & $\mathrm{~d} 4.5 \pm 0.5$ & do & 50 \\
\hline \multirow[t]{9}{*}{2.} & $\begin{array}{l}\text { Leaf } \\
\text { mid rib }\end{array}$ & & & & & & & & & & & \\
\hline & & 12 & - & - & - & $3.9 \pm 0.4$ & b $2.3 \pm 0.4$ & c5.3 \pm 0.5 & b $2.4 \pm 0.5$ & a $1.9 \pm 0.5$ & $\begin{array}{l}\text { minmum } \\
\text { shooting/rooting }\end{array}$ & 60 \\
\hline & & 15 & - & - & - & 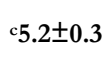 & b $2.7 \pm 0.5$ & c5.8 \pm 0.5 & b2.9 \pm 0.5 & ab $2.2 \pm 0.5$ & $\begin{array}{l}\text { maximum } \\
\text { shooting/rooting }\end{array}$ & 60 \\
\hline & & - & 12 & - & - & a3.6 \pm 0.5 & a $1.9 \pm 0.5$ & b4.4 \pm 0.3 & b $2.3 \pm 0.5$ & a1.8 \pm 0.3 & $\begin{array}{l}\text { minimum } \\
\text { shooting/rooting }\end{array}$ & 60 \\
\hline & & - & 15 & - & - & b4 $4.5 \pm 0.3$ & b $2.4 \pm 0.1$ & c $5.3 \pm 0.3$ & c3.6 \pm 0.5 & b $2.7 \pm 0.5$ & do & 60 \\
\hline & & - & - & 12 & - & nil & nil & nil & $\mathrm{e} 5.1 \pm 0.5$ & c3.5 \pm 0.4 & direct rooting only & 50 \\
\hline & & - & - & 15 & - & nil & nil & nil & e $5.8 \pm 0.5$ & с $3.8 \pm 0.5$ & do & 50 \\
\hline & & - & - & - & 12 & nil & nil & nil & $\mathrm{e} 5.5 \pm 0.5$ & $\mathrm{~d} 4.5 \pm 0.5$ & do & 50 \\
\hline & & - & - & - & 15 & nil & nil & nil & $\mathrm{f} 6.5 \pm 0.5$ & $\mathrm{~d} 4.7 \pm 0.5$ & do & 50 \\
\hline \multirow[t]{9}{*}{3.} & Petiole & & & & & & & & & & & \\
\hline & & 12 & - & - & - & $3.6 \pm 0.5$ & a1.6 \pm 0.3 & $4.7 \pm 0.5$ & a1.9 \pm 0.3 & a $1.5 \pm 0.2$ & $\begin{array}{l}\text { minimum } \\
\text { shooting/rooting }\end{array}$ & 60 \\
\hline & & 15 & - & - & - & b $4.4 \pm 0.2$ & a $1.9 \pm 0.3$ & c5.3 \pm 0.3 & ${ }^{\mathrm{b}} 2.4 \pm 0.1$ & a $1.7 \pm 0.2$ & do & 60 \\
\hline & & - & 12 & - & - & $3.4 \pm 0.2$ & a $1.4 \pm 0.2$ & a3.9 \pm 0.5 & a1.9 \pm 0.4 & a1.4 \pm 0.3 & do & 60 \\
\hline & & - & 15 & - & - & $3.8 \pm 0.5$ & a1.9 \pm 0.3 & b4 $4 \pm 0.5$ & с3.3 $3 \pm 0.5$ & b $2.4 \pm 0.3$ & do & 60 \\
\hline & & - & - & 12 & - & nil & nil & nil & $\mathrm{d} 4.1 \pm 0.2$ & b $2.7 \pm 0.3$ & direct rooting only & 50 \\
\hline & & - & - & 15 & - & nil & nil & nil & $\begin{array}{c}\mathrm{e} \\
5.0 \pm 0.2\end{array}$ & 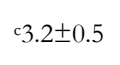 & do & 50 \\
\hline & & - & - & - & 12 & nil & nil & nil & $\mathrm{e} 5.2 \pm 0.3$ & с3.3 20.5 & do & 50 \\
\hline & & - & - & - & 15 & nil & nil & nil & $\begin{array}{c}\mathrm{e} \\
5.5 \pm 0.6\end{array}$ & c3.6 \pm 0.5 & do & 50 \\
\hline \multirow[t]{6}{*}{4.} & $\begin{array}{l}\text { Shoot } \\
\text { tip }\end{array}$ & & & & & & & & & & & \\
\hline & & 12 & - & - & - & b $4.3 \pm 0.5$ & b $2.3 \pm 0.4$ & с $5.4 \pm 0.3$ & b $2.6 \pm 0.3$ & a1.9 \pm 0.4 & $\begin{array}{l}\text { direct } \\
\text { shooting/rooting }\end{array}$ & 60 \\
\hline & & 15 & - & - & - & c5.2 \pm 0.1 & $\mathrm{~b} 2.6 \pm 0.5$ & $\begin{array}{c}\text { c5.9土. } \\
3\end{array}$ & b $2.9 \pm 0.5$ & b $2.3 \pm 0.5$ & do & 60 \\
\hline & & - & 12 & - & - & a $3.7 \pm 0.4$ & a1.9 \pm 0.5 & a $4.7 \pm 0.4$ & b2.7 \pm 0.3 & a1.9 \pm 0.5 & do & 60 \\
\hline & & - & 15 & - & - & b $4.5 \pm 0.5$ & b2.5 \pm 0.2 & с5.3 \pm 0.2 & c3.8 \pm 0.5 & b $2.7 \pm 0.3$ & do & 60 \\
\hline & & - & - & 12 & - & nil & nil & nil & $\mathrm{e} 5.3 \pm 0.2$ & ь $2.7 \pm 0.5$ & only rooting & 50 \\
\hline
\end{tabular}




\begin{tabular}{|c|c|c|c|c|c|c|c|c|c|c|c|c|}
\hline & & - & - & 15 & - & nil & nil & nil & $\begin{array}{c}\mathrm{e} \\
51+01\end{array}$ & c3.1 \pm 0.2 & do & 50 \\
\hline & & - & - & - & 12 & nil & nil & nil & $\begin{array}{c}\mathrm{e} \\
5.2 \pm 0.3\end{array}$ & c3.4 \pm 0.5 & do & 50 \\
\hline & & - & - & - & 15 & nil & nil & nil & $\begin{array}{c}\mathrm{e} \\
5.6 \pm 0.5 \\
\end{array}$ & 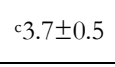 & do & 50 \\
\hline \multirow{2}{*}{\multicolumn{13}{|c|}{$\begin{array}{l}\text { Values are represented as mean } \pm \mathrm{SD}(\mathrm{n}=10) \text {, Data was analyzed by ANOVA using Duncan's multiple range test (SPSS17.0); the } \\
\text { values with different superscript along the columns are statistically significant at } \mathrm{P}<0.005 \text {, Data scored after } 12 \text { weeks of culture } \\
\text { period } \\
\text { Table } 7 \text {. Direct organogenesis on MS medium with different concentrations of cytokinins on multiple } \\
\text { shoot regeneration/rooting from in-vitro explants of } R \text {. webbianum }\end{array}$}} \\
\hline & & & & & & & & & & & & \\
\hline $\begin{array}{l}\text { Sr. } \\
\text { No. }\end{array}$ & Explants & $\begin{array}{l}\text { BAP } \\
(\mu \mathbf{M})\end{array}$ & $\begin{array}{l}\text { TDZ } \\
(\mu \mathrm{M})\end{array}$ & $\begin{array}{l}\mathrm{KN} \\
(\mu \mathrm{M})\end{array}$ & $\begin{array}{c}\mathrm{Z} \\
(\mu \mathrm{M})\end{array}$ & $\begin{array}{l}\text { Shoot } \\
\text { No. }\end{array}$ & $\begin{array}{c}\text { Shoot } \\
\text { length } \\
(\mathrm{cm})\end{array}$ & $\begin{array}{c}\text { Leaf } \\
\text { No./shoot }\end{array}$ & $\begin{array}{l}\text { Root } \\
\text { No. }\end{array}$ & $\begin{array}{c}\text { Root } \\
\text { length } \\
(\mathrm{cm})\end{array}$ & Response & $\begin{array}{c}\% \\
\text { response }\end{array}$ \\
\hline \multirow[t]{7}{*}{1.} & Leaf & & & & & & & & & & & \\
\hline & & 12 & - & - & - & c5.4 \pm 0.3 & b2.4 \pm 0.2 & $\mathrm{~d} 6.3 \pm 0.5$ & nil & Nil & $\begin{array}{l}\text { direct shooting } \\
\text { only }\end{array}$ & 70 \\
\hline & & 15 & - & - & - & 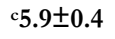 & b $2.4 \pm 0.3$ & е $7.2 \pm 0.1$ & nil & nil & do & 70 \\
\hline & & - & 12 & - & - & b $4.9 \pm 0.2$ & a1.9 \pm 0.3 & c5.9 \pm 0.5 & a1.9 \pm 0.3 & a $1.4 \pm 0.3$ & $\begin{array}{l}\text { direct } \\
\text { shooting/rooting }\end{array}$ & 70 \\
\hline & & - & 15 & - & - & 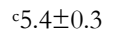 & b $2.3 \pm 0.2$ & $\mathrm{~d} 6.3 \pm 0.3$ & b2.3 20.4 & ${ }^{a} 1.7 \pm 0.3$ & do & 70 \\
\hline & & - & - & 12 & - & с $5.0 \pm 0.5$ & a $1.3 \pm 0.2$ & 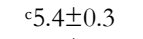 & a $1.7 \pm 0.5$ & a $1.2 \pm 0.5$ & do & 70 \\
\hline & & - & - & 15 & - & 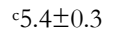 & a1.7 \pm 0.3 & 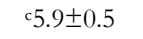 & b2. $4 \pm 0.5$ & a1.6 \pm 0.4 & do & 70 \\
\hline \multirow[t]{7}{*}{2.} & $\begin{array}{l}\text { Leaf } \\
\text { mid rib }\end{array}$ & & & & & & & & & & & \\
\hline & & 12 & - & - & - & с $5.7 \pm 0.5$ & b $2.5 \pm 0.4$ & $\mathrm{~d} 6.6 \pm .5$ & nil & Nil & $\begin{array}{l}\text { direct maximum } \\
\text { shooting only }\end{array}$ & 70 \\
\hline & & 15 & - & - & - & d $6.2 \pm 0.3$ & b $2.6 \pm 0.3$ & e $7.4 \pm 0.5$ & a1.7 \pm 0.3 & a1.9 \pm 0.2 & $\begin{array}{l}\text { direct } \\
\text { shooting/rooting }\end{array}$ & 70 \\
\hline & & - & 12 & - & - & с $5.4 \pm 0.2$ & b $2.3 \pm 0.5$ & $\mathrm{~d} 6.3 \pm 0.5$ & b $2.4 \pm 0.3$ & a1. $6 \pm 0.2$ & $\begin{array}{l}\text { direct shooting } \\
\text { /rooting }\end{array}$ & 70 \\
\hline & & - & 15 & - & - & $c 5.8 \pm 0.3$ & b2.6 \pm 0.5 & $\mathrm{~d} 6.6 \pm 0.3$ & b $2.7 \pm 0.5$ & a1.9 \pm 0.3 & do & 70 \\
\hline & & - & - & 12 & - & с5.3 \pm 0.1 & $\mathrm{a} 1.7 \pm 0.2$ & c5.9 \pm 0.4 & $\begin{array}{c}\mathrm{b} \\
2.1 \pm 0.3\end{array}$ & a1.6 \pm 0.2 & do & 70 \\
\hline & & - & - & 15 & - & с5.6 \pm 0.2 & a1.9 \pm 0.3 & $\mathrm{~d} 6.3 \pm 0.5$ & b $2.3 \pm 0.4$ & a1.8 \pm 0.4 & do & 70 \\
\hline \multirow[t]{7}{*}{3.} & Petiole & & & & & & & & & & & \\
\hline & & 12 & - & - & - & c5.3 \pm 0.4 & b2. $5 \pm 0.3$ & $\mathrm{~d} 6.2 \pm 0.1$ & nil & Nil & $\begin{array}{l}\text { direct shooting } \\
\text { only }\end{array}$ & 70 \\
\hline & & 15 & - & - & - & c5.7 \pm 0.5 & a1.4 \pm 0.3 & е $7.3 \pm 0.5$ & nil & nil & $\begin{array}{l}\text { direct shooting } \\
\text { only }\end{array}$ & 70 \\
\hline & & - & 12 & - & - & b4.8 \pm 0.3 & a1.8 \pm 0.3 & $c 5.9 \pm 0.3$ & $\mathrm{a} 1.7 \pm 0.3$ & a $1.3 \pm 0.2$ & $\begin{array}{l}\text { direct } \\
\text { shooting/rooting }\end{array}$ & 70 \\
\hline & & - & 15 & - & - & с $5.3 \pm 0.2$ & b $2.3 \pm 0.5$ & $\mathrm{~d} 6.4 \pm 0.5$ & a1.9 \pm 0.5 & a1.6 \pm 0.3 & do & 70 \\
\hline & & - & - & 12 & - & b4. $4 \pm 0.3$ & a $1.3 \pm 0.2$ & с $5.5 \pm 0.4$ & $1.6 \pm 0.2$ & $\mathrm{a} 1.2 \pm 0.1$ & do & 70 \\
\hline & & - & - & 15 & - & с $5.3 \pm 0.4$ & a1.5 \pm 0.2 & 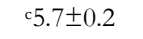 & a1.8 \pm 0.3 & a $1.4 \pm 0.1$ & do & 70 \\
\hline \multirow[t]{7}{*}{4.} & $\begin{array}{l}\text { Shoot } \\
\text { tip }\end{array}$ & & & & & & & & & & & \\
\hline & & 12 & - & - & - & c5.6 \pm 0.3 & b2.7 \pm 0.4 & $\mathrm{~d} 6.6 \pm 0.5$ & nil & Nil & $\begin{array}{l}\text { direct shooting } \\
\text { only }\end{array}$ & 70 \\
\hline & & 15 & - & - & - & ${ }^{\mathrm{d}} 6.4 \pm 0.4$ & b $2.7 \pm 0.3$ & $\begin{array}{c}\text { e } 7.6 \pm 0 . \\
5\end{array}$ & b2.5 \pm 0.3 & $\mathrm{a} 1.7 \pm 0.2$ & $\begin{array}{l}\text { direct } \\
\text { shooting/rooting }\end{array}$ & 70 \\
\hline & & - & 12 & - & - & 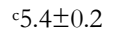 & b2.5 \pm 0.2 & $\mathrm{~d} 6.5 \pm 0.5$ & b2.3 \pm 0.5 & a1.6 \pm 0.2 & do & 70 \\
\hline & & - & 15 & - & - & с5.8 \pm 0.4 & b2.5 \pm 0.2 & $\mathrm{~d} 6.6 \pm 0.4$ & b $2.4 \pm 0.5$ & a $1.8 \pm 0.2$ & do & 70 \\
\hline & & - & - & 12 & - & с $5.4 \pm 0.2$ & ${ }^{a} 1.8 \pm 0.2$ & ${ }^{\mathrm{d}} 6.1 \pm 0.3$ & b2.3 \pm 0.1 & ${ }^{a} 1.7 \pm 0.3$ & do & 70 \\
\hline & & - & - & 15 & - & с $5.5 \pm 0.3$ & a $1.9 \pm 0.3$ & ${ }^{\mathrm{d}} 6.2 \pm 0.5$ & b2.4 \pm 0.1 & $\mathrm{a} 1.8 \pm 0.4$ & do & 70 \\
\hline
\end{tabular}

Values are represented as mean \pm SD $(\mathrm{n}=10)$, Data was analyzed by ANOVA using Duncan's multiple range test (SPSS17.0); the values with different superscript along the columns are statistically significant at $\mathrm{P}<0.005$, Data scored after 12 weeks of culture period

Table 8. Direct organogenesis on MS medium with $15 \mu \mathrm{M}$ BAP and different concentrations of auxins on multiple shoot regeneration/rooting from in-vitro explants of R. webbianum

\begin{tabular}{|c|c|c|c|c|c|c|c|c|c|c|c|c|}
\hline \multirow{2}{*}{$\begin{array}{l}\text { Sr. } \\
\text { No. }\end{array}$} & \multicolumn{2}{|l|}{ Cytokinin } & \multicolumn{3}{|c|}{ Auxins } & \multirow{2}{*}{$\begin{array}{l}\text { Shoot } \\
\text { No. }\end{array}$} & \multirow{2}{*}{$\begin{array}{l}\text { Shoot } \\
\text { length } \\
\text { (cm) }\end{array}$} & \multirow{2}{*}{ Leaf no. } & \multirow{2}{*}{ Root No } & \multirow{2}{*}{$\begin{array}{l}\text { Root } \\
\text { length } \\
\text { (cm) }\end{array}$} & \multirow{2}{*}{ Response } & \multirow{2}{*}{$\begin{array}{l}\% \\
\text { Respon } \\
\text { se }\end{array}$} \\
\hline & BAP $(\mu \mathrm{M})$ & $\begin{array}{l}2,4-\mathrm{D} \\
(\mu \mathrm{M})\end{array}$ & $\begin{array}{l}\text { NAA } \\
(\mu \mathrm{M})\end{array}$ & $\begin{array}{l}\text { IBA } \\
(\mu \mathrm{M})\end{array}$ & $\begin{array}{l}\text { IAA } \\
(\mu \mathrm{M})\end{array}$ & & & & & & & \\
\hline \multirow[t]{5}{*}{1.} & Leaf & & & & & & & & & & & \\
\hline & 15 & 15 & - & & & $\mathrm{d} 8.9 \pm 0.5$ & c $3.7 \pm 0.2$ & $\mathrm{~g} 10.3 \pm 0.5$ & c $3.7 \pm 0.4$ & b2.9 \pm 0.5 & $\begin{array}{l}\text { multiplication } \\
\text { / elongation/ } \\
\text { rooting }\end{array}$ & 70 \\
\hline & 15 & & 15 & & & $\mathrm{~d} 8.6 \pm 0.5$ & с $3.3 \pm 0.2$ & f9. $4 \pm 0.3$ & c3.9 \pm 0.3 & c $3.2 \pm 0.5$ & do & 70 \\
\hline & 15 & & - & 15 & & е9.4 \pm 0.5 & c $3.7 \pm 0.3$ & $\mathrm{~g} 10.7 \pm 0.5$ & e $5.9 \pm 0.5$ & $\mathrm{~d} 4.4 \pm 0.3$ & do & 80 \\
\hline & 15 & & - & & 15 & е9. $1 \pm 0.5$ & c $3.3 \pm 0.3$ & $\mathrm{~g} 10.2 \pm 0.5$ & e $5.5 \pm 0.5$ & $\mathrm{~d} 4.1 \pm 0.3$ & do & 80 \\
\hline
\end{tabular}




\begin{tabular}{|c|c|c|c|c|c|c|c|c|c|c|c|c|}
\hline \multirow[t]{5}{*}{2.} & Mid rib & & & & & & & & & & & \\
\hline & 15 & 15 & & & & f9. $3 \pm 0.5$ & c $3.7 \pm 0.2$ & $\mathrm{~g} 10.4 \pm 0.5$ & c $3.8 \pm 0.4$ & c $3.3 \pm 0.5$ & do & 70 \\
\hline & 15 & & 15 & & & $\mathrm{e} 8.7 \pm 0.5$ & c $3.5 \pm 0.3$ & f9. $5 \pm 0.4$ & $\mathrm{~d} 4.3 \pm 0.2$ & c $3.5 \pm 0.4$ & do & 70 \\
\hline & 15 & & & 15 & & f9.7 \pm 0.5 & c3.9 \pm 0.3 & $\mathrm{~g} 10.9 \pm 0.5$ & $\mathrm{f} 6.3 \pm 0.5$ & $\mathrm{~d} 4.5 \pm 0.3$ & do & 80 \\
\hline & 15 & & & & 15 & f $9.2 \pm 0.5$ & c $3.5 \pm 0.3$ & g10.6 0.5 & f $6.1 \pm 0.5$ & $\mathrm{~d} 4.2 \pm 0.3$ & do & 80 \\
\hline \multirow[t]{5}{*}{3.} & Petiole & & & & & & & & & & & \\
\hline & 15 & 15 & & & & e $8.7 \pm 0.3$ & c $3.4 \pm 0.2$ & f9. $9 \pm 0.5$ & c $3.5 \pm 0.2$ & b $2.7 \pm 0.3$ & do & 70 \\
\hline & 15 & & 15 & & & e $8.5 \pm 0.3$ & c $3.4 \pm 0.2$ & f9. $3 \pm 0.5$ & c $3.7 \pm 0.2$ & b $2.9 \pm 0.3$ & do & 70 \\
\hline & 15 & & - & 15 & & f9. $.2 \pm 0.5$ & c3.8 \pm 0.3 & $\mathrm{~g} 10.3 \pm 0.5$ & e $5.8 \pm 0.3$ & $\mathrm{~d} 4.3 \pm 0.2$ & do & 80 \\
\hline & 15 & & - & & 15 & e $8.8 \pm 0.5$ & c $3.5 \pm 0.3$ & f9. $9 \pm 0.5$ & e $5.4 \pm 0.3$ & $\mathrm{~d} 4.1 \pm 0.2$ & do & 80 \\
\hline \multirow[t]{5}{*}{4.} & Shoot tip & & & & & & & & & & & \\
\hline & 15 & 15 & & & & f9. $5 \pm 0.5$ & с $3.9 \pm 0.2$ & $\mathrm{~g} 10.7 \pm 0.5$ & 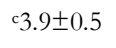 & c $3.3 \pm 0.2$ & do & 70 \\
\hline & 15 & & 15 & & & e $8.9 \pm 0.5$ & с3.6 \pm 0.2 & $\mathrm{~g} 10.5 \pm 0.3$ & $\mathrm{~d} 4.2 \pm 0.5$ & c $3.4 \pm 0.2$ & do & 70 \\
\hline & 15 & & - & 15 & & f9. $7 \pm 0.5$ & c3.9 \pm 0.3 & $\mathrm{~g} 10.8 \pm 0.5$ & $\mathrm{f} 6.2 \pm 0.5$ & $\mathrm{~d} 4.6 \pm 0.3$ & do & 80 \\
\hline & 15 & & - & & 15 & f $9.1 \pm 0.5$ & c $3.4 \pm 0.3$ & $\mathrm{~g} 10.3 \pm 0.5$ & е $5.8 \pm 0.5$ & $\mathrm{~d} 4.3 \pm 0.3$ & do & 80 \\
\hline
\end{tabular}

Values are represented as mean \pm SD $(n=10)$, Data was analyzed by ANOVA using Duncan's multiple range test (SPSS17.0); the values with different superscript along the columns are statistically significant at $\mathrm{P}<0.005$, Data scored after 12 weeks of culture period

The plant formation on auxins from all the in-vitro explants was found on MS $+15 \mu \mathrm{M} 2,4-\mathrm{D}$ and from cytokinins was found on MS $+15 \mu \mathrm{M}$ BAP with $70 \%$ response (Fig. 21) and the combination of phytohormones i.e. $15 \mu \mathrm{M}$ BAP $+10 \mu \mathrm{M}$ IBA, complete plant formation was also observed with $80 \%$ response (Fig. 22). Only rooting was observed on IAA and IBA when used individually and the rooting was maximum on $15 \mu \mathrm{M}$ IBA with $70 \%$ response (Fig. 23). It was observed that at low concentrations of BAP and $\mathrm{KN}$ only shooting was observed.

The effect of $15 \mu \mathrm{M}$ of auxins on different in-vitro explants was studied for shoot regeneration as shown in Fig. d refer to Table 6. The different concentrations ( 5 to $15 \mu \mathrm{M}$ ) were used, but the maximum shoot regeneration was observed at $15 \mu \mathrm{M}$. The maximum shoot regeneration was found in case of leaf midrib and shoot tip i.e. 5 shoots per explants without callus formation (Fig. 24 and 25). No shoot regeneration was found in case of IAA and IBA, only rooting was observed even at higher concentrations.

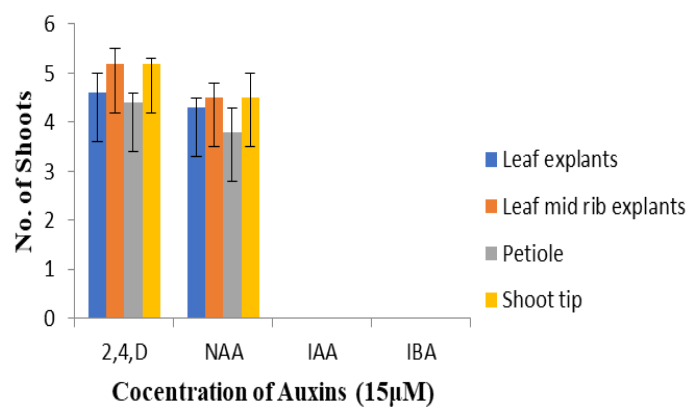

Fig.d. Effect of Auxins on shoot regeneration from in-vitro explants
The Fig. e shows data taken from Table 7, in which maximum shoot regeneration was observed on $15 \mu \mathrm{M}$ cytokinins i.e. BAP, TDZ and $\mathrm{KN}$. The different concentrations of cytokinins were used for regeneration studies, out of which $15 \mu \mathrm{M}$ BAP showed maximum shoot regeneration on different explants. The maximum shoot number was observed on $15 \mu \mathrm{M}$ BAP using shoot tip explants i.e. 6 shoots per explants (Fig. 26).

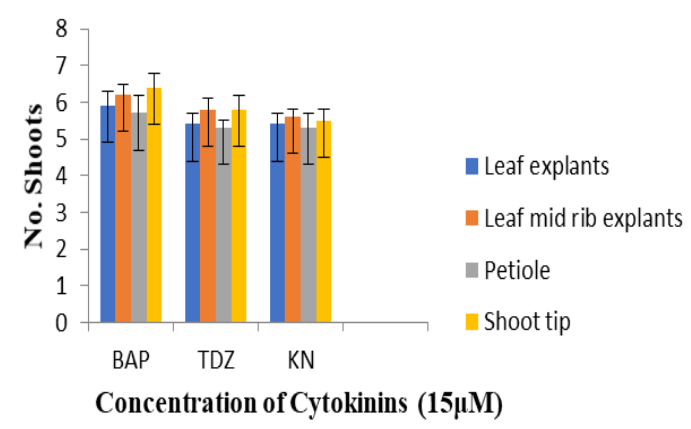

Fig.e. Effect of cytokinins on shoot regeneration from in-vitro explants

Based on the data available in the Table 8 , the following Fig. $\mathbf{f}$ shows the effect of combination of phytohormones i.e. cytokinins $(15 \mu \mathrm{M}$ BAP) with $15 \mu \mathrm{M}$ auxins, (2,4-D, NAA, IAA and IBA) on regeneration from different explants. However, different concentrations were used, but maximum shoot regeneration was observed on $15 \mu \mathrm{M}$. This was also observed that the combination of $15 \mu \mathrm{M}$ BAP with $15 \mu \mathrm{M}$ IBA showed best results i.e. 10 shoots per explants, in case of leaf midrib and shoot tip explants along with rooting (Fig. 27). 


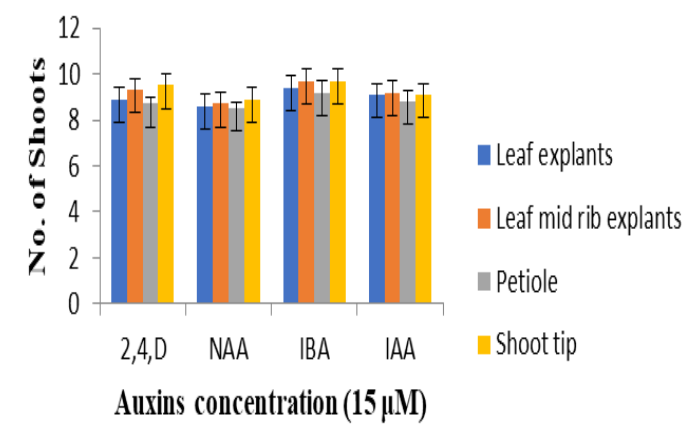

Figure f: Effect of BAP $15(\mu \mathrm{M})$ with auxins on shoot regeneration from in-vitro explants

\section{Discussion}

In present studies, the main aim was the micropropagation of the $R$. webbianum as it is vulnerable and now endangered species. These have vanished from lower altitudes and now found only on high altitudes of Kashmir Himalaya, so the micropropagation is best way towards conservation of these plants. R. webbianum showed good growth response i.e, upto $70 \%$ as it was collected from very cold region i.e. Ladakh, which is also known as cold desert and remains, covered with snow for 8 months in a year.

In order to prevent and to avoid the contamination to carry out tissue culture experiments, the explants surface sterilization was done using different sterilants. The seeds and field grown plants were sterilized with different concentrations of $\mathrm{HgCl}_{2}$ and $\mathrm{NaOCl}$ and good results were achieved on $\mathrm{HgCl} 2$. In contrast to our results, Farzami and Ghorbanli (2005) performed sterilization of seeds of $R$. ribes $L$. after immersing them in $0.3 \%$ of benomil solution for $1 \mathrm{~h}$, and then transferred to ethanol for 1 minute and then to $\mathrm{NaOCl}(50 \%)$ for10 minutes. In present study, it was observed that the seeds of Rheum webbianum showed 100\% germination on MS medium when treated with different phytohormones, but according to Farzami and Ghorbanli (2002 \& 2005) the seedling formation on MS basal medium in $R$. ribes was achieved after chilling for three days with GA3. No GA3 was used in the present study. Combinations of different phytohormones were used on different explants. Field grown material showed only callus formation, especially in leaf. The seedlings were further used as explants. Different parts of seedlings were used i.e., leaf and petiole. The callus formed was soft, friable, regenerative and green. The callus was sub-cultured further to get regeneration. After sub culturing the callus on different phytohormones, it showed organogenesis. Both rooting and shooting was also observed. In order to get direct rooting, these in-vitro shoots were also sub-cultured on different concentrations of phytohormones.
R. webbianum showed best shoot regeneration on concentration of $15 \mu \mathrm{M}$ BAP and $15 \mu \mathrm{M} 2,4-\mathrm{D}$ and also on combination of $15 \mu \mathrm{M}$ BAP with $15 \mu \mathrm{M}$ IBA on MS medium. These results are in line with that of Lal and Ahuja (1989) who reported the in vitro propagation of Indian rhubarb ( $R$. emodi) on MS medium supplemented with BAP and IBA. Our results were also supported by various workers like Roggemans and Claes (1979), Roggemans and Boxus (1988) (R. rhaponticum), Farzami and Ghorbanli (2005) (R. ribes), Thomas and Sharon (2005) (R. rbubarbarum, R. rbaponticum, R. undulatum), Malik et al., (2010) (R. emodi) who also reported formation of multiple shoots on MS supplemented with BAP and IBA. However, Verma et al., (2012) reported formation of multiple shoots in $R$. emodi on MS with BAP and IAA. On the other hand, Walkey (1968) reported plantlet formation of $R$. rhaponticum using LS medium instead of MS medium.

Shoot multiplication of $R$. webbianum on MS medium from leaf was also observed when the medium was supplemented with different concentrations of BAP, Kinetin or TDZ. Similar results were obtained by Walkey and Mathews (1979), Roggemans and Boxus (1988) (R. rhaponticum) on MS medium when supplemented with Kinetin; but Lal and Ahuja (1989) reported that Kinetin did not show any response when shoot tips of R. emodi were cultured on it. It seems that it is basically the endogenous level of hormones that play a vital role in exhibiting the regeneration potential of a species. In $R$. webbianum, it was noticed that BAP shows better results than Kinetin, TDZ and Zeatin, and it has also been reported by Murashige (1974) and Street (1977) which is attributed to group localized at N6 position of cytokinin (Narayanaswamy 1977). Lal and Ahuja (1989) in R. emodi has reported decrease in multiple shoot formation with increase in concentration of BAP. Chin (1993) also reported that low concentration of TDZ are effective for micropropagation, which is in contrast to our results.

Number of shoots, size of shoots and leaf showed increase with increase in concentration of phytohormones. The maximum shoot length in Rheum species was observed on BAP $15 \mu \mathrm{M}+$ IAA $15 \mu \mathrm{M}$; BAP $15 \mu \mathrm{M}+\mathrm{IBA} 15 \mu \mathrm{M}$; Kinetin, TDZ, 2,4$\mathrm{D}$ and NAA $15 \mu \mathrm{M}$ combined with IAA and IBA showed maximum shoot formation and elongation. These results are similar to the reports of $\mathrm{Hu}$ and Wang (1983), and with Wareing and Phillips (1981). Shoot formation on BAP and Kinetin is again supported by Lal and Ahuja (1989, 2000), Malik et al., (2009) reported shoot regeneration from leaves of $\mathrm{R}$. emodi using BAP in MS medium. Rooting on MS medium was achieved with different phytohormones which is strikingly different from those who report rooting on basal medium without 
using any phytohormones. Walkey and Mathews (1979) in R. rhaponticum, Malik et al., 2009 in R. emodi. In present studies, the maximum rooting was observed on IBA and IAA; and 2,4-D and NAA. These results are similar to those of Roggemans and Claes (1979) and Roggmans and Boxus (1988) who initiated roots in $\mathrm{R}$. rhaponticum on MS + IBA, Lal and Ahuja $(1989,1993)$ in R. emodi on MS + IBA; Ishimaru et al., (1990) in R. palmatum on MS +NAA; Thomas and Sharon (2005) on MS +IAA in R. rhubarbarum, R. rhaponticum, R. undulatum, but the reports of Farzami and Ghorbanli. (2005) showed the formation of maximum roots on half strength $\mathrm{MS}+\mathrm{IBA}$ in $\mathrm{R}$. ribes. When $\mathrm{BAP}$ was used in high concentration i.e, $15 \mu \mathrm{M}$, shooting as well as low rooting was recorded in R.webbianum. Similarly, when 2, 4-D and NAA was used in high concentration low shooting and high rooting was observed. In present studies, IAA and IBA showed good response for rooting and BAP showed good response for shoot formation in $R$. webbianum, and this result is more or less similar to the report given by Parveen et al., (2012).

The in-vitro raised plantlets were transferred first to plastic pots and later on to nursery where survival $50 \%$ for R. webbianum which is quite contrary to the results of Lal and Ahuja $(1989,1993)$ who reported hardening of in-vitro raised plantlets of R. emodi with 89\%-90\% survival rate, in R. emodi (Roggemans \& Boxus 1988).

\section{Conclusion}

As we already knows plants are very essential and important part of our our daily lives. All living creatures are directly and indirectly dependent on plants. The plants are micro-biosynthetic factories for a variety of compounds which are their secondary metabolites. The medicinal properties are attributed to specific combination of bioactive phytochemicals. The medicinal plants are being used by human being since time immemorial and we get reference to these in ancient literature. As per WHO estimates, about $80 \%$ world population still relies on traditional system of medicine. Plant based drugs are preferred over synthetic ones because these are cheap, with less side effects and biocompatibilities with the human bodies. Due to recent resurgence in interest in plant-based drugs, their demand has increased manifold. Further, most of these plants are collected from the wild source in unplanned and unscientific way with destructive harvesting without following for sustainable supply. India is one of the largest suppliers of raw materials of medicinal plants with a foreign trade of over USD 1 billion per annum and has a great potential for cultivation of these medicinal plants.

Rheum with 60 species in the world, is represented by 7 species in high altitudinal area of North India. The different species are demarcated on the basis of various morphological characters of stem leaf and inflorescence. Due to high medicinal value, it is being over exploited and has been included in red list of threatened species of IUCN, thus necessitating the need for conservation and cultivation. The medicinal value of rhubarb is attributed to anthraquinones or their derivatives such as rhein, emodin, aloe-emodin, chrysaphanol, physicion and rutin.

R. webbianum are endangered species and they have vanished from lower altitudes. At present, they have shown their presence only on high altitudes of Kashmir Himalaya, so the various tissue culture techniques including micropropagation are best way towards conservation of this plant. Besides, efficient use these technologies can provide the germplasms required for ex situ conservation and cultivation of these species. In the present study, different media were used i.e. MS medium, LS medium and Nitsch \&Nitsch medium. But the MS medium showed best results. Seed germination with complete seedling was observed on MS medium with different concentrations of phytohormones in which shooting and rooting both was observed. The best results for plant regeneration were obtained in BAP and IBA. The different concentrations of cytokinins and auxins were used. The best results were observed on BAP, 2,4-D, TDZ, Kinetin, IBA and IAA. Further, sub-culturing was done using small portions of leaf and petiole in different concentrations of phytohormones with MS medium. The best results were observed on BAP, 2,4-D. The green compact, friable, regenerative and soft callus was formed after sub culturing. The callus obtained from different explants was further sub cultured on different concentrations of phytohormones with MS medium. The plant formation was observed on different concentrations of BAP, 2,4-D, KN and NAA and TDZ. But the best result were found on high concentrations of phytohormones i.e. $15 \mu \mathrm{M}$, especially BAP.

R. webbianum was treated with combination of phytohormones i.e. $15 \mu \mathrm{M}$ BAP with $15 \mu \mathrm{M}$ IBA, the maximum shoot regeneration was observed from leaf callus and petiole callus. For direct organogenesis, these explants were sub cultured again. The maximum direct shoot regeneration was found on $15 \mu \mathrm{M} 2,4-\mathrm{D}$ from leaf and petiole. While using cytokinins, $15 \mu \mathrm{M}$ BAP showed maximum shoot regeneration on leaf. The best result was found on combination of phytohormones i.e. $15 \mu \mathrm{M}$ BAP with $15 \mu \mathrm{M}$ IBA. The response of this species was observed upto $70 \%$. Hardening of in-vitro raised plants was done by gradual shifting from plastic pots containing autocalved soil, sand and peat mixed with MS medium to the soil pots with covering of transparent polythene paper placed in the culture room for 15 days and then these pots transferred to net house and kept for 10 days. After 10 days all the plants were taken out from pots and 
were sown directly in soil of net house. The plants showed good growth response for conservation.

\section{Author's contributions}

All authors equally participated in designing experiments analysis and interpretation of data. All authors read and approved the final manuscript.

\section{Acknowledgement}

This study was supported by DST, and DBT(IPLS) GoI, New Delhi funded entrepreneurship project, the assistance of which is highly acknowledged.

\section{References}

1. Akerele, O. WHO guidelines for the assessment of herbal medicine. Phytotherapy Research, 1992, 62, 99-110.

2. Anjen, L., Alisa, E.G., Suk-pyo, H., McNeill, J., Hideaki, O., Park, C. and Liao, M.. Flora of China, 2003, 5, 278-315.

3. Anonymous. Pharmacopoeia of India, 4th edition: Government of India, Ministry of Health, Controller of publication, New Delhi, 1996, 53-55.

4. Anonymous. 'Quality Control Methods for Medicinal Plant Materials' World Health Organization, Geneva, 1998.

5. Bapat, V. A., Yadav, S. R. and Dixit, G. B. Rescue of endangered plants through biotechnological applications. National Academy Science Letters, 2008, 31, 201-210.

6. Borgia, M., Sepe, N., Borgia, R. and Ori-Bellometti, M. Pharmacological activity of an herbal extract: controlled clinical study. Current Therapeutic Research, 1981, 29, 525-36.

7. Bourgaud, F., Gravot, A., Milesi, S. and Gontier, E. Production of plant secondary metabolites: a historical perspective. Plant Science, 2001, 161, 839851.

8. Castleman, M. The Healing Herbs: The Ultimate guide to the curative powers of nature's medicine. Emmaus, PA: Rodale Press, 1991, 305-307.

9. Chaurasia, O. P. and Ballabh, B. Medicinal Plants of cold desert Ladakh used in treatment of stomach disorders. Indian Journal of Traditional Knowledge, 2009, 82, 185-192.

10. Chaurasia, O. P., Ahmed, Z. and Ballabh, B. Ethnobotany and Plant of Trans-Himalaya Satish Serial Publishing House, Delhi, India, 2007, 1-544.

11. Chin, Y. L. The use of thidiazuron in tissue culture. In vitro Cellular and Developmental Biology-Plant, 1993, 29, 92-96.

12. Dornenburg, H. and Knorr, D. Strategies for the improvement of secondary metabolite production in plant cell cultures. Enzyme and Microbial Technology, 1995, 17, 674-684.
13. Duke, J.A. Green Pharmacy: New Discoveries in Herbal Remedies for Common Diseases and Conditions from the World's Foremost Authority on Healing Herbs. Emmaus, Pennsylvania: Rodale Press, ISBN 0-87596-316-1, 1997, 507.

14. Farzami S. and Ghorbanli, M. Effects of nutritional factors on the formation of anthraquinones in callus cultures of Rheum ribes. Plant Cell, Tissue and Organ culture, 2002, 68, 171-175.

15. Farzami, M. S. and Ghorbanli, M. Formation of catechin in callus cultures and micropropagatlon of Rheum ribes L. Pakistan Journal of Biological Sciences, 2005, 8, 1346-1350.

16. Ganie, A. H., Tali, B. A., Khuroo, A. A., Nawchoo, I. A. and Rather, A. M. Rheum spiciforme Royle (Polygonaceae): A new record to the flora of Kashmir Valley, India. National Academy Science Letters, 2014, 37, 561-565.

17. Goyal, H. Cytogenetical and chemical characterization of some selected North Indian medicinal Composits. A Ph. D. Thesis. Department of Botany, Punjabi University, Patiala 2013.

18. Hinchee, M. A. W., Corbin, D. R., Armstrong, C. L., Fry, J. E., Sato, S. S., Deboer, D. L., Petersen, W. L., Armstrong, T. A., Connor-Wand, D. Y., Layton, J. G. and Horsch, R. B. Plant transformation in Plant Cell and Tissue Culture. In: Vasil LK, Thorpe TA, editors. Dordrecht: Kluwer Academic, 1994, 231270 .

19. Ishimaru, K., Satake, M. and Shimomura, K. Production of $(+) /$-Catechin in root and cell suspension cultures of Rheum palmatum L. Plant tissue culture letters, 1990, 7, 159-163.

20. Kala, C. P. Status and conservation of rare and endangered medicinal plant in the Indian transHimalaya. Biological Conservation, 2000, 93, 371379 .

21. Kala, C. P., Dhyani, P. P. and Sajwan, B. S. Developing the medicinal plant sector in north india: challenges and opportunities. Journal of ethnobiology and ethnomedicine, 2006, 2, 32.

22. Lal, N. and Ahuja, P. S. Propagation of Indian rhubarb (Rheum emodi Wall.) using shoot tip and leaf explants culture. Plant Cell Reports, 1989. 8, $439-496$

23. Lal, N. and Ahuja, P. S. Assessment of liquid culture procedures for in-vitro propagation of Rheum emodi. Plant Cell, Tissue and Organ Culture, 1993, $34,223-226$

24. Lal, N. and Ahuja, P. S. Adventitious shoot bud formation from cultured leaf explants of Rheum emodi wall. Plant tissue culture, 2000, 12, 173-180.

25. Malik, S., Kumar, R., Vats, S. K., Bhushan, S., Sharma, M. and Ahuja, P. S. Regeneration in Rheum emodi Wall:: a step towards conservation of an 
endangered medicinal plant species. Engineering in Life Sciences, 2009, 9, 130-134.

26. Malik, S., Sharma, N., Sharma, U. K., Singh, N. P., Bhushan, S., Sharma, M., Sinha, A. K. and Ahuja, P. S. Qualitative and quantitative analysis of anthraquinone derivatives in rhizomes of tissue culture-raised Rheum emodi Wall. Plants. Journal of Plant Physiology, 2010, 167, 749-756.

27. Mukherjee, P. K. and Wahile, A. Integrated approaches towards drug development from Ayurveda and other Indian system of medicines. Journal of Ethnopharmacology, 2006, 103, 25-35

28. Murashige, T. Plant propagation through tissue culture, Annual Review of Plant Physiology, 1974, $25,135-165$.

29. Murch, S. J., Peiris, S. E., Shi, W. L., Zobayed, S. M. A. and Saxena, P. K. Genetic diversity in seed populations of Echinacea purpurea controls the capacity for regeneration, route of morphogenesis and phytochemical composition. Plant Cell Reports, 2006, 25, 522-532.

30. Nadeem, M., Rikhari, H.C., Kumar, A., Palni, L. M. S. and Nandi, N. K. Taxol content in the bark of Himalayan yew in relation to tree age and sex. Phytochemistry, 2002, 60, 627-631.

31. Narayanaswamy, S. Regeneration of plants from tissue cultures. In: Plant cell, tissue and organ culture (Reinert, J. Bajaj, Y. P. S. eds.), Springer-Verlag, 1977, 179-248.

32. Nautiyal, B. P., Prakash, V., Maithani, U. C., Chauhan, R. S., Purohit, H. and Nautiyal, M. C. Germinability, productivity and economic viability of Rheum emodi Wall. ex Meissn. cultivated at lower altitude. Current Science, 2003, 84, 143-148.

33. Parveen, S. and Wani, N. A. Germanibility, conservation and cultivation of Rheum emodi Wall ex. Meissner - A threatened medicinal plant. International journal of life sciences, Biotechnology and Pharma research, 2013, 2, 163-168.

34. Peigen, X., Liyi, $H$. and Liwei, W. Ethnopharmacologic study of Chinese rhubarb. Journal of Ethnopharmacology, 1984, 10, 275-293.

35. Phartyal, S. S., Thapliyal, R. C., Koedam, N. and Godefroid, S. Ex situ conservation of rare and valuable forest tree species through seed gene bank. Current Science, 2002, 83, 1351-1357.

36. Prakash, A., Prasad, G. B. K. S. and Dua, V. K. Anti-inflammatory activity of different fractions of Leucas cephalotes leaves extract. International Journal of Current Pharmaceutical Review and Research, 2011, 1, 28-32.

37. Qu, L. Wang, X. Yang, J., Hood, E. and Scalzo, R. 2004. Ethephon promotes germination on Echinacea aungustifolia and E. pallida in darkness. HortScience, 39: 1101-1103.
38. Ramachandra Rao, S. and Ravishankar, G. A. Plant cell cultures: chemical factories of secondary metabolites. Biotechnology Advances, 2002, 20, 101-153.

39. Ramakrishna, A. and Ravishankar, G. A. Influence of abiotic stress signals on secondary metabolites in plants. Plant Signaling Behaviour, 2011, 6, 17201731.

40. Roggemans, J. and Boxus, P. Rhubarb (Rheum rbaponticum L.). In: Biotechnology in Agriculture and Forestry, 6. Crops II (ed) Y. P. S. Bajaj, SpringerVerlag, Berlin, Germany, 1988, 339-350.

41. Roggemans, J. and Claes, M. C., Rapid clonal propagation of rhubarb by in-vitro culture of shoot tips. Scientia Horticulturae, 1979. ,11, 241-246.

42. Schippmann, U. W. E., Leaman, D. and Cunningham, A. B. A comparison of cultivation and wild collection of medicinal and aromatic plants under sustainability aspects. In: R. J. Bogers, L. E. Craker and Lange D (eds), Medicinal and Aromatic Plants, 2006, 75-95.

43. Sen, J. and Sharma, A. K. Micropropagation of Withania somnifera from germinating seeds and shoot tips. Plant Cell Tissue and Organ Culture, 1991, 26: 71-73

44. Sharma, N. Cytomorphological diversity and chemical characterization of selected anti-diabetic medicinal plants from North India. A Ph. D. Thesis. Department of Botany, Punjabi University, Patiala. 2012.

45. Sharma, V., Sharma, N., Singh, H., Srivastava, D.K., Pathania, V., Singh, B. and Gupta, R.C. Comparative account on GC-MS analysis of Mentha arvensis Corn Mint from three different loacations of North India. International Journal of Drug Development and Research, 2009, 1, 1-9.

46. Srinivas, G., Babykutty, S., Sathiadevan, P.P. and Srinivas, P. Molecular mechanism of emodin action: transition from laxative ingredient to an antitumor agent. Medicinal Research Reviews, 2007, 27, 591 608.

47. Stewart, R. R. An Annotated Catalogue of Vascular Plants of West Pakistan and Kashmir; Fakhri Printing Press, Karachi, Pakistan, 1972, 1028.

48. Stockigt, J., Obitz, P., Falkenhagen, H., Lutterbach, R. and Endre, S.. Natural products and enzymes from plant cell cultures. Plant Cell, Tissue and Organ Culture, 1995, 43, 97-109.

49. Street, H. E. Plant tissue and cell culture, 2 edn. London, Edinburgh, Melbourne: Blackwell Scientific Publications 1977.

50. Tayade, A., Dhar, P., Ballabh, B., Kumar, R., Chaurasia, O. P., Bhatt, R. P. and Srivastava, R. B. Rheum webbianum Royle: a potential medicinal plant from trans-himalayan cold deserts of ladakh, India. Plant Archives, 2012, 12, 603-606 
51. Thomas, J. and Sharon, H. Investigation of Rhubarb virus diseases -A scoping study. A Report of a project commissioned and funded by Grow com 2005.

52. Thomas, J. and Sharon, H. Investigation of Rhubarb virus diseases -A scoping study. A Report of a project commissioned and funded by Grow com 2005.

53. Verma, P., Mathur, A. K., Jain, S. P. and Mathur, A. In-vitro Conservation of twenty-three overexploited Medicinal Plants belonging to the Indian sub continent, Scientific World Journal, Article ID 9296502012.
54. Walkey, D. G. A. The production of virus free rhubarb by apical culture. Journal of Horticulture Science, 1968, 43, 281-287.

55. Walkey, D. G. A. and Mathews, K. A. Rapid clonal propagation of rhubarb (Rheum rhaponiticum L) from meristem tips in tissue culture. Plant Science Letters, 1979, 14, 287- 290.

\section{Cite this article as:}

Shagoon Tabin, Azra N. Kamili, R.C. Gupta. Micropropagation and conservation of Rheum webbianum collected from Zanaskar valley via Tissue culture. Annals of Plant Sciences 7.4 (2018) pp. 2187-2203.

do $\mathrm{http://dx.doi.org/10.21746/aps.2018.7.4.4}$

Source of support: DST, and DBT(IPLS) GoI, New Delhi

Conflict of interest: Ni 